\title{
Recent progress of graphene oxide-based multifunctional nanomaterials for cancer treatment
}

\author{
Lijun Liu ${ }^{1 \dagger}$, Qingming Ma ${ }^{1 \dagger}$, Jie Cao ${ }^{1}$, Yang Gao', Shangcong Han', Yan Liang ${ }^{1}$, Tingting Zhang ${ }^{1}$, \\ Yang Song ${ }^{2}$ and Yong Sun ${ }^{1 *}$ (])
}

\author{
*Correspondence: \\ sunyong@qdu.edu.cn \\ ${ }^{\dagger}$ Lijun Liu and Qingming Ma \\ contributed equally to this \\ work \\ ${ }^{1}$ Department \\ of Pharmaceutics, School \\ of Pharmacy, Qingdao \\ University, Qingdao 266071, \\ China \\ Full list of author information \\ is available at the end of the \\ article
}

\begin{abstract}
Background: In the last decade, graphene oxide-based nanomaterials, such as graphene oxide (GO) and reduced graphene oxide ( $\mathrm{rGO}$ ), have attracted more and more attention in the field of biomedicine. Due to the versatile surface functionalization, ultra-high surface area, and excellent biocompatibility of graphene oxide-based nanomaterials, which hold better promise for potential applications than among other nanomaterials in biomedical fields including drug/gene delivery, biomolecules detection, tissue engineering, especially in cancer treatment.
\end{abstract}

Results: Here, we review the recent progress of graphene oxide-based multifunctional nanomaterials for cancer treatment. A comprehensive and in-depth depiction of unique property of graphene oxide-based multifunctional nanomaterials is first interpreted, with particular descriptions about the suitability for applying in cancer therapy. Afterward, recently emerging representative applications of graphene oxide-based multifunctional nanomaterials in antitumor therapy, including as an ideal carrier for drugs/genes, phototherapy, and bioimaging, are systematically summarized. Then, the biosafety of the graphene oxide-based multifunctional nanomaterials is reviewed.

Conclusions: Finally, the conclusions and perspectives on further advancing the graphene oxide-based multifunctional nanomaterials toward potential and versatile development for fundamental researches and nanomedicine are proposed.

Keywords: Nanomaterials, Graphene oxide, Caner treatment, Drug and gene delivery, Phototherapy, Bioimaging

\section{Background}

Cancer has always been a serious threat to human life and health, which needs to be solved urgently. Although traditional therapeutic strategies including chemotherapy together, radiotherapy, and surgery (Peer et al. 2007) have demonstrated plenty of achievements, they are still limited in clinical applications due to drawbacks like multidrug resistant (MDR) effect, poor bioavailability, and non-specific biodistribution in the body (Yi et al. 2019; Yan et al. 2021). To improve the safety and effectiveness of tumor therapy, the development of 
a novel anticancer therapeutic strategy becomes one of the key issues. In recent years, new methods facilitated by using nanomaterials show great promises in anticancer treatment (Qian et al. 2017; Yan et al. 2018, 2020).

As a shining star among nanomaterials, graphene oxide-based nanomaterials have gained significant research interests globally ever since it was first demonstrated in the year of 2004 (Kakran et al. 2011). In 2008, Dai's research team first demonstrated that polyethylene glycol (PEG)-GO can be used as a versatile platform for delivering anticancer drugs delivery. The investigation of graphene oxide-based nanomaterials has opened new perspectives for cancer treatment with improved therapeutic efficiency (Liu et al. 2008).

Graphene oxide-based nanomaterials, GO and rGO, have unique property including chemical and mechanical stability, two-dimensional structures, and biocompatibility. Moreover, they have a large and easy-to-modify surfaces that can be modified to link with epoxide hydroxyl, carboxyl, and hydroxy $(-\mathrm{O}-,-\mathrm{COOH},-\mathrm{OH})$ groups. These groups can be further used to change the surface characteristic of $\mathrm{GO}$ and provide attachment sites to various molecules, including protein, deoxyribonucleic acid (DNA), and ribonucleic acid (RNA) (Yang et al. 2013a, b). Therefore, graphene oxide-based nanomaterials are well-situated in various applications, including drug/gene delivery, phototherapy, and bioimaging (Byun and Lee 2014; Chen et al. 2014a, b, c; Kim et al. 2011a, b; Qiao et al. 2019; Ma et al. 2020a, b, c; Zhang et al. 2021; Ma et al. 2021; Gao et al. 2021; Wang et al. 2021), which overall show great potentials in cancer treatment (Durán et al. 2015). Every year, a large number of research papers regarding graphene oxide-based nanomaterials in cancer treatment are published and therefore a timely review to summarize the new findings is particularly necessary. Moreover, existing literatures always focus on confined aspects of graphene oxidebased nanomaterials, a comprehensive summary covering all the aspects, ranging from the fundamentals to synthesis and applications, is of great significance.

In this review, we summarize the recent advanced investigations of graphene oxide-based nanomaterials in anticancer therapy. The surface properties, biocompatibility, photothermal properties, and $\mathrm{pH}$ sensitivity of graphene oxide-based nanomaterials are first interpreted, with the description of GO and its application forms. Then, the latest achievements of graphene oxide-based nanomaterials in cancer treatment such as delivering anticancer drugs and genes, phototherapy, and bioimaging, are summarized. Afterward, the biosafety of graphene oxide-based nanomaterials is reviewed, including biotoxicity, blood compatibility, immune compatibility, and inflammation. Finally, a conclusion on further advancing graphene oxide-based nanomaterials in antitumor therapy is discussed.

\section{Materials and methods}

Not applicable.

\section{Results and discussion}

Properties of graphene oxide-based nanomaterials

\section{Surface properties}

GO typically contains both hydrophobic and hydrophilic regions. In the hydrophobic region, the $\pi-\pi$ conjugated system on the surface makes it capable of connecting multiple molecules through the non-covalent bond interactions (Karlický et al. 2013). Moreover, GO has better water solubility than graphene due to its abundant hydrophilic 
groups, such as $-\mathrm{O}-,-\mathrm{COOH},-\mathrm{OH}$. These groups could form the hydrophilic region, which allows further functionalization by attaching to various molecules including protein, DNA, and RNA (Yang et al. 2013a, b). Besides, compared with GO, the oxygen content, surface charge, and hydrophilicity of rGO are less, enabling rGO with restored electrical conductivity, enhanced optical absorbance, and a flat region for loading cargos (Kim et al. 2011a, b).

\section{Biocompatibility}

The structure of graphene oxide-based nanomaterials endows them with amphiphilicity, which makes them show good dispersibility in a variety of solvents. However, many studies have indicated that GO tends to form aggregates in high-concentration salt or protein solutions, thus reducing its biocompatibility (Song et al. 2014; Yang et al. 2011). At present, the biocompatibility of graphene oxide-based nanomaterials can be improved through surface engineering (Miyanda and Gautam 2017). For example, by modifying with chitosan (CS), the hemolytic activity of GO can be eliminated largely (Wu et al. 2015).

\section{Photothermal property}

Under near-infrared radiation, photon energy can be converted to heat through nonradiative decay transitions, which can be applied for tumor treatment. Graphene oxidebased nanomaterials can absorb NIR radiation and convert it to heat (Gong et al. 2018; Huang et al. 2014). The non-covalent bond interactions on the surface of graphene oxide-based nanomaterials can be weakened due to the temperature rise and atomic vibration. Therefore, graphene oxide-based nanomaterials can not only be used directly in photothermal therapy, but also can be applied to quickly release goods from the surface through near-infrared radiation (Kalluru et al. 2016).

\section{pH sensitivity}

The surface properties of graphene oxide-based nanomaterials can usually be affected by $\mathrm{pH}$ changes. $\mathrm{GO}$ are stable at a $\mathrm{pH}$ of 7 or 8 and are less stable in the $\mathrm{pH}$ range of 3 to 12 (Chen et al. 2013a, b). Compared with the microenvironment of normal tissues (pH 7.4), tumor tissues are usually more acidic ( $\mathrm{pH} \sim 6.8)$ microenvironment (Zhou et al. 2014). At lower $\mathrm{pH}$ values, protonation weakens the hydrogen bond interaction between the drug and GO. This unique property of graphene oxide-based nanomaterials can be been incorporated into the design of a pH-sensitive anticancer drug delivery system.

\section{Graphene oxide-based nanomaterials}

Graphene oxide-based nanomaterials contain "pristine" GO, rGO, and modified graphene oxide nanocomposites. The methods of synthesizing graphene oxide-based nanomaterials are listed in Table 1.

\section{Graphene oxide and its derivatives}

In the typical synthesis of GO, graphite powder is oxidized with various oxidants in an acidic environment, and then GO can be obtained by ultrasonication or mechanical stir (Fig. 1) (Bai et al. 2011). There are many classic methods for synthesizing GO, including 
Table 1 Summary of common chemical synthetic methods to generate graphene oxide-based nanomaterials

\begin{tabular}{|c|c|c|c|}
\hline Type & Method & Reaction condition & Ref. \\
\hline \multirow[t]{3}{*}{ GO } & \multirow[t]{3}{*}{ Chemical oxidation } & $\mathrm{KClO}_{3} /$ fuming $\mathrm{HNO}_{3}$ & Brodie (1859) \\
\hline & & $\mathrm{NaNO}_{3} / \mathrm{KMnO}_{4} /$ concentrated $\mathrm{H}_{2} \mathrm{SO}_{4}$ & Hummers Jr and Offeman (1958) \\
\hline & & $\mathrm{KMnO}_{4} / \mathrm{H}_{2} \mathrm{SO}_{4} / \mathrm{H}_{3} \mathrm{PO}_{4}$ & Marcano et al. (2010) \\
\hline rGO & Chemical reduction & $\begin{array}{l}\text { Hydrazine, hydrazine hydrate, L-ascorbic } \\
\text { acid }\end{array}$ & Lin et al. (2016) \\
\hline \multirow{2}{*}{$\begin{array}{l}\text { Graphene } \\
\text { oxide } \\
\text { derivatives }\end{array}$} & Covalent & $\begin{array}{l}\text { Amine coupling to carboxylic groups; } \\
\text { sulfonylation, acylation }\end{array}$ & \\
\hline & Non-covalent & $\begin{array}{l}\text { van der Waals forces, electrostatic } \\
\text { interactions, hydrogen bonding, } \pi-\pi \\
\text { stacking interactions }\end{array}$ & Zhang et al. (2017a, b, c, d, e) \\
\hline
\end{tabular}

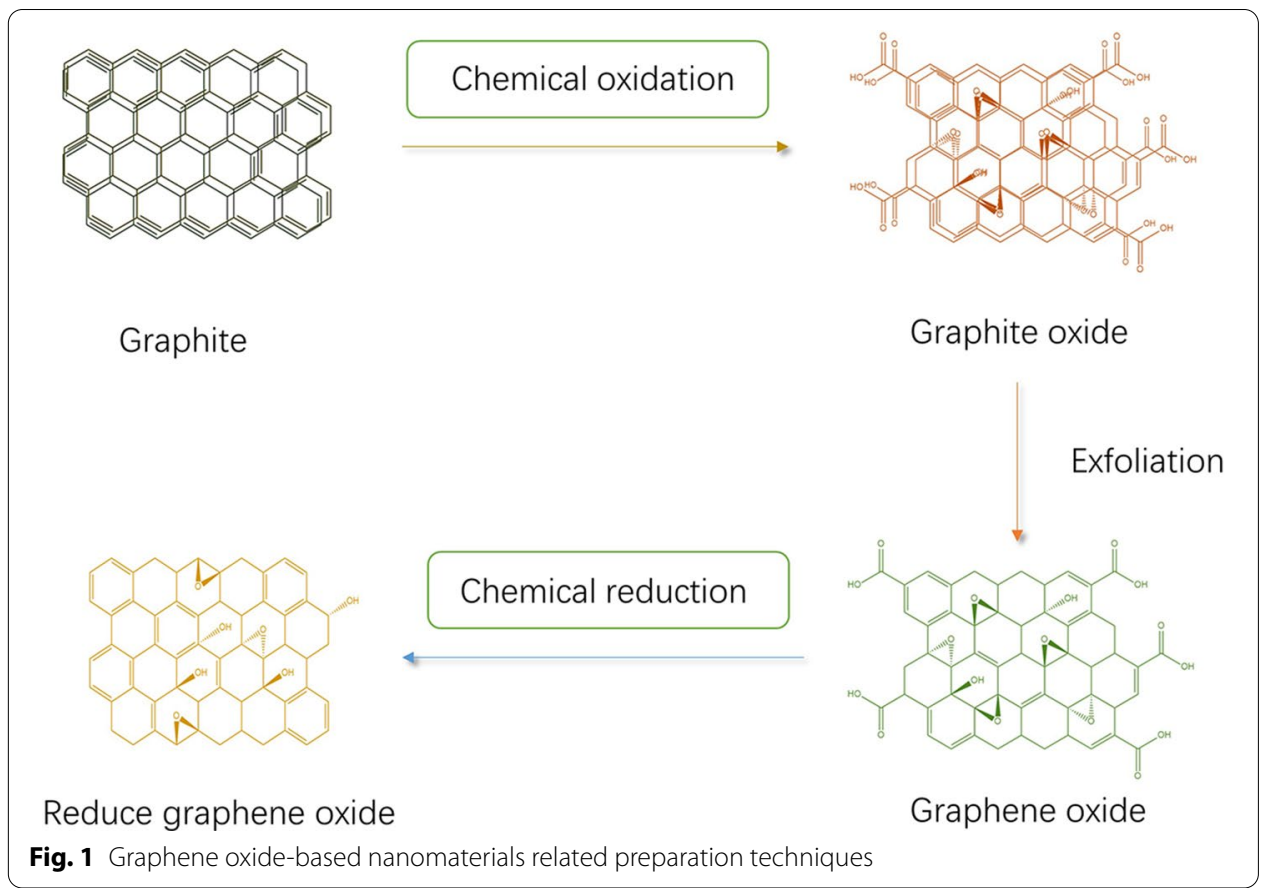

the Brodie method (Brodie 1859), Hummers method (Hummers Jr and Offeman 1958), and Marcano method (Marcano et al. 2010).

rGO is a derivative of GO and can be produced by the reduction treatment of GO with reducing agents, such as hydrazine, hydrazine hydrate, and L-ascorbic acid (Lin et al. 2016).

\section{Graphene oxide nanocomposites}

To functionalized graphene oxide-based nanomaterials, various components have been incorporated to functionalize graphene oxide nanocomposites. Typical components used for functionalized graphene oxide-based nanomaterials include synthetic polymers like PEG, poly-L-lysine (PLL), poly-vinylalcohol (PVA), and Pluronic F127 (PF127) (Liu et al. 2008; Sun et al. 2008; Xu et al. 2015; Du et al. 2014; Li et al. 2014; Rosenthal et al. 
2018; Chen et al. 2013a, b, 2017a; Rao et al. 2018; Wu et al. 2014; Aliabadi et al. 2017; Zhang et al. 2018), and natural polymers like CS, sodium alginate (SA), dextran (DEX), L-cysteine, and gelatin (Fan et al. 2016; Ege et al. 2017; Mu et al. 2015; Tikhonov et al. 2006; Desbrières et al. 1996; Zhao et al. 2018; Li et al. 2015, 2016; Liu et al. 2011; Alibolandi et al. 2017) (Fig. 2).

Furthermore, the functionalization of graphene oxide-based nanomaterials can be achieved by covalent modification and noncovalent methods (Georgakilas et al. 2012). Covalent modification, involving amine coupling to carboxylic groups, sulfonylation, acylation, is one of the most applied methods (Chua and Pumera 2013). This approach may destroy the original structure of GO that the hybridization of $\mathrm{sp}^{2}$ carbon atoms of the $\pi$-network into $\mathrm{sp}^{3}$ configuration, but it can obtain better stability in the physiological solution. Non-covalent modification can be achieved by Van der Waals forces, electrostatic interactions, hydrogen bonding, and $\pi-\pi$ stacking interactions. This method does not affect the native structure and $\pi$-network of GO, but it also may increase the instability of the resultant materials (Zhang et al. 2017a, b, c, d, e).

\section{Application form}

\section{Nanoparticles}

Graphene oxide-based nanoparticles have attracted extensive interests due to their distinct characteristics, such as high stability amphiprotic, and high encapsulation capacity of drugs (Ma et al. 2020a, b, c). Polymer-functionalized graphene oxide nanoparticles

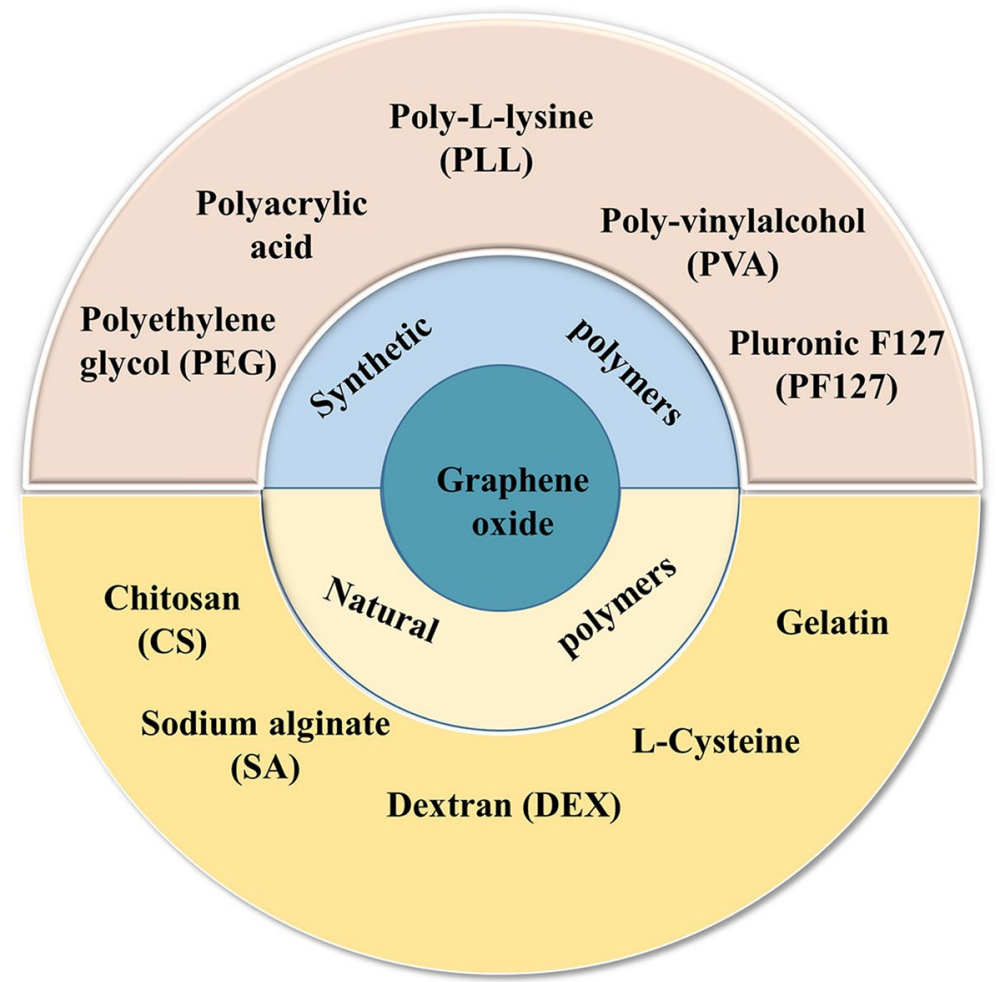

Fig. 2 Materials used for surface modification of GO 
and GO-metal nanoparticles are well-recognized types (Lu et al. 2019). Polymer-functionalized graphene oxide nanoparticles can be divided into two categories, one is modified with natural polymers such as CS, hypocrellin A (HA), the other is modified with PEG, poly-ethylenimine (PEI), polyacrylic acid (PAA), and other synthetic polymers. For GO-metal nanoparticles, GO is combined with metal nanoparticles including silver nanoparticles (AgNPs) and gold nanoparticles (AuNPs).

\section{Other forms}

Graphene oxide-based nano-sheets are also applied in the treatment of tumors. For example, graphene oxide nanosheets have been used to treat human hepatocellular carcinoma (HCC) due to its apoptotic effect in human liver cancer (HepG2) cells (Loutfy et al. 2017). Other experiments showed that resveratrol rGO nanosheets can cause a dose-dependent membrane leakage and oxidative stress in A2780 ovarian cancer cells, which would reduce their viability via apoptosis confirmed by the upregulation of apoptosis executioner caspase-3 (Gurunathan et al. 2015). Gurunathan et al. (2013) demonstrated that both GO nanosheets and bacterially reduced graphene oxide (B-rGO) nanosheets have dose-dependent toxicity on human breast cancer cells, the dose is more than $60 \mu \mathrm{g} / \mathrm{ml}$ had obvious cytotoxicity.

\section{Applications of graphene oxide-based nanomaterials in cancer therapy}

Graphene oxide-based nanomaterials have been widely applied in cancer therapy, including drug/gene delivery, biological imaging, biosensing (Komisar et al. 2020; Chung et al. 2013), tissue engineering (Ghosh and Chatterjee 2020; Zhao 2019; Dinescu et al. 2019; Olad and Hagh 2019; Liu et al. 2018; Shin et al. 2017; Cao et al. 2017; Díez-Pascual and Díez-Vicente 2016; Ma et al 2020a, b, c; Ramalingam et al. 2013), and antibacterial (Ma et al. 2011; Xu et al. 2011; Zhang et al. 2019; Abed et al. 2020; Lin et al. 2016, 2020; Pang et al. 2019; Zhi et al. 2013; Chowdhury et al. 2015; Shen et al. 2012; Shi et al. 2013; Li et al. 2013; Sheng et al. 2013; Gollavelli and Ling 2012). In this section, we will give an overview of recent achievements regarding applying graphene oxide-based nanocomposites for anticancer therapy, particularly for drug/gene delivery, phototherapy, bioimaging (Fig. 3).

\section{Advanced delivery system}

In the past few years, graphene oxide-based nanomaterials have been extensively studied as a new type of nanocarriers, which is used to deliver various therapeutic anticancer agents (Sharma and Mondal 2020), such as chemotherapeutic drugs, antibodies, DNA, RNA, and genes. In this section, we will discuss the application of graphene oxide-based nanomaterials for delivering anticancer drugs and genes, as shown in Table 2.

Drug delivery Various anticancer drugs have been widely used in clinical treatment, such as camptothecin (CPT), paclitaxel (PTX), and doxorubicin hydrochloride (DOX) (Ma et al. 2017, 2020a, b, c). However, there are still some severe challenges in the process of practical application, including the lack of patient compliance, targeting delivery, and controlled release. Graphene oxide-based nanomaterials are considered as an ideal candidate for drug delivery due to its high loading efficiency, low toxicity, excellent properties, 


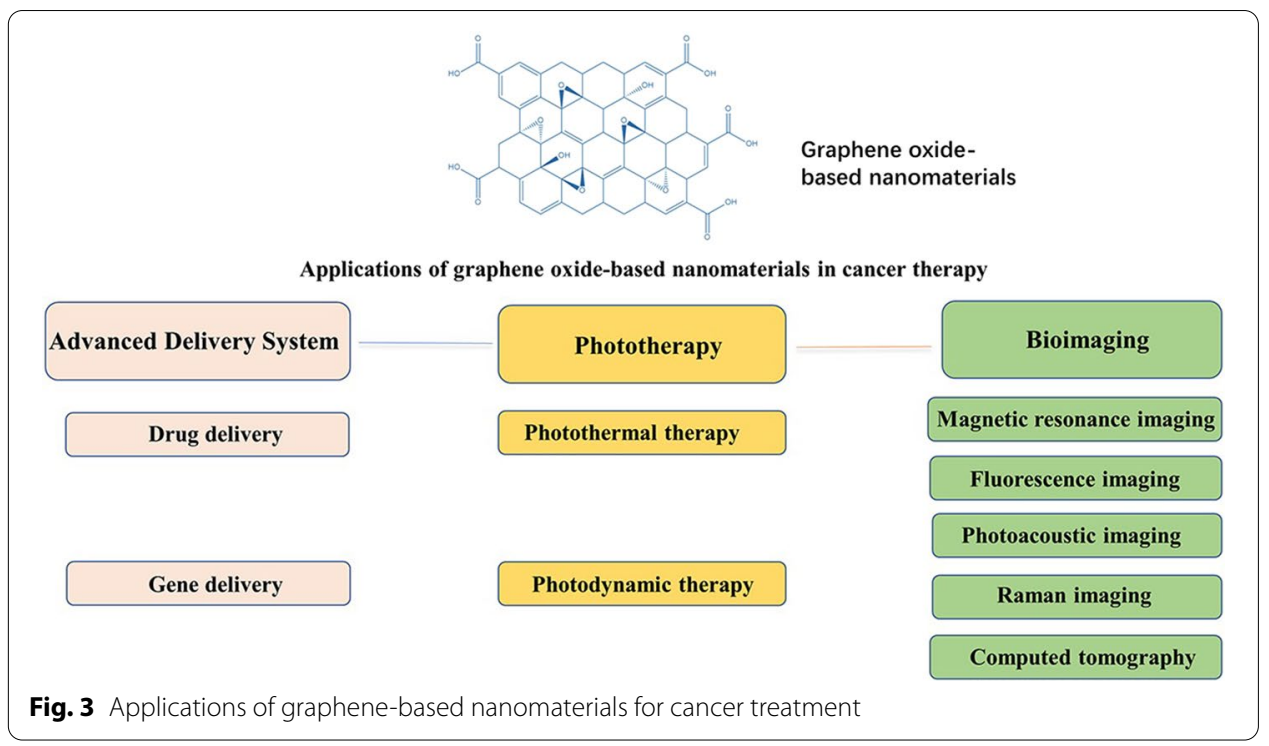

and good water solubility. Firstly, the hydrophobic structure of GO is suitable for loading drugs through the non-covalent bond, especially $\pi-\pi$ stacking and hydrophobic interaction. Secondly, specific geometry with a double side of GO can provide a high surface area, which is conducive to drug loading. Meanwhile, GO has hydrophilic groups such as hydroxyl, carboxyl, and epoxy, which can offer reactive sites to connect functional molecules to improve anticancer efficacy (Liu et al. 2013a, b, c; Lv et al. 2016). Liu et al. (2008) have shown that PEG-modified GO could form complex with active metabolite 7-ethyl10-hydroxycamptothecin (SN38) via Van der Waals forces for colon cancer therapy, and the toxicity was more than that of irinotecan by 2 to 3 orders of magnitude. Through $\pi-\pi$ stacking and hydrophobic interaction, other chemotherapy drugs such as PTX can also be loaded in PEG-GO and exhibit a concentration- and time-dependent manner. Meanwhile, PEG-GO-PTX shows a higher cytotoxicity effect and excellent bioavailability than free PTX (Xu et al. 2014).

Various specific targets exist on tumor cytomembrane, including folic acid (FA) receptor, HA receptor, transferrin (Tf) receptor, cell attach molecular receptor (CAMR), vascular endothelial growth factor receptor (VEGFR), and epidermal growth factor receptor (EGFR) (Lee et al. 2016), which offer the potentials for graphene oxide-based nanomaterials to actively target on tumor. For example, Liu et al. (2018) synthesized a novel FA-modified fluorinated graphene oxide (FGO) carrier for DOX delivery, which exhibited higher selectivity toward tumor cells compare with FGO. Ma et al. (2017) prepared a new actively targeted drug carrier system of FA-bovine serum albumin (BSA)/ GO, which used FA as a targeting agent and BSA protein as a stabilizer. The toxicities of the nanocomplexes FA-BSA/GO and FA-BSA/GO/DOX were estimated in MCF-7 and lung adenocarcinoma (A549) cells. Results showed the cellular uptake efficiency of FA-BSA/GO/DOX by MCF-7 cells, overexpressed FA receptors was much higher than that of BSA/GO/DOX. After the incubation of A549 cells, a normal cell with low-level FA-receptor expression, treated by FA-BSA/GO/DOX and BSA/GO/DOX, the halfmaximum inhibitory concentration $\left(\mathrm{IC}_{50}\right)$ values of the two groups were very similar. 
Table 2 Applications of graphene oxide-based nanomaterials for anticancer drug and gene delivery

\begin{tabular}{|c|c|c|c|c|}
\hline Nanocomposites & $\begin{array}{l}\text { Delivered drug/ } \\
\text { gene }\end{array}$ & $\begin{array}{l}\text { Fabrication } \\
\text { method }\end{array}$ & $\begin{array}{l}\text { Highlights of the } \\
\text { study }\end{array}$ & Ref. \\
\hline PEG-GO-SN38 & SN38 & $\begin{array}{l}\text { Non-covalent inter- } \\
\text { actions }\end{array}$ & $\begin{array}{l}\sim 30 \% \text { release in } \\
\text { serum; IC } C_{50} \text { values: } \\
\sim 6 \mathrm{nM}\end{array}$ & Liu et al. (2008) \\
\hline PEG-GO-PTX & PTX & $\begin{array}{l}\text { Non-covalent inter- } \\
\text { actions }\end{array}$ & $\begin{array}{l}\text { Low concentration } \\
\text { and short time, for } \\
\text { improving the bio- } \\
\text { availability of PTX }\end{array}$ & Xu et al. (2014) \\
\hline FA-FGO-DOX & DOX & $\begin{array}{l}\text { Non-covalent inter- } \\
\text { actions }\end{array}$ & $\begin{array}{l}\text { Much higher cancer } \\
\text { cell inhibition than } \\
\text { pure DOX under } \\
\text { the same condi- } \\
\text { tions }\end{array}$ & Liu et al. (2018) \\
\hline FA-BSA-GO-DOX & DOX & $\begin{array}{l}\text { Non-covalent inter- } \\
\text { actions }\end{array}$ & $\begin{array}{l}\text { Drug loading effi- } \\
\text { ciency at } 30.43 \% ; \\
\text { higher drug } \\
\text { release at pH } 5.0\end{array}$ & Ma et al. (2017) \\
\hline GA-GO-DOX & DOX & $\begin{array}{l}\text { Non-covalent inter- } \\
\text { actions }\end{array}$ & $\begin{array}{l}\text { High anti-prolifer- } \\
\text { ative effect on } \\
\text { tumor cells }\end{array}$ & $\begin{array}{l}\text { Nascimento et al. } \\
(2016)\end{array}$ \\
\hline CS-GO-DOX & DOX & $\begin{array}{l}\text { Non-covalent inter- } \\
\text { actions }\end{array}$ & $\begin{array}{l}\text { Higher drug release } \\
\text { at pH 5.3; better } \\
\text { inhibitory effect on } \\
\text { tumor growth }\end{array}$ & Wang et al. (2018) \\
\hline GO-MS-CPT & CPT & Adsorption & $\begin{array}{l}\text { Stimuli-responsive } \\
\text { controlled release }\end{array}$ & Tran et al. (2018) \\
\hline NGO-SS-DOX & DOX & Covalent grafting & $\begin{array}{l}\text { Redox-responsive } \\
\text { controlled release }\end{array}$ & $\begin{array}{l}\text { Chen et al. (2014a, } \\
\text { b, c) }\end{array}$ \\
\hline GO-ssDNA & ssDNA & $\begin{array}{l}\text { Non-covalent inter- } \\
\text { actions }\end{array}$ & $\begin{array}{l}\text { GO platform for the } \\
\text { detection of DNA }\end{array}$ & Lu et al. (2009) \\
\hline GOCLNPs-pDNA & pDNA & $\begin{array}{l}\text { Non-covalent inter- } \\
\text { actions }\end{array}$ & $\begin{array}{l}\text { Achieved binding to } \\
\text { double-stranded } \\
\text { DNA }\end{array}$ & Di Santo et al. (2019) \\
\hline $\begin{array}{l}\text { GO-FACO+-SiRNA- } \\
\text { DOX }\end{array}$ & siRNA & $\begin{array}{l}\text { Non-covalent inter- } \\
\text { actions }\end{array}$ & $\begin{array}{l}\text { Targeted delivery for } \\
\text { drugs and genes }\end{array}$ & Cao et al. (2013) \\
\hline $\begin{array}{l}\text { PEG-PEI-FA-GO- } \\
\text { SiRNA }\end{array}$ & siRNA & $\begin{array}{l}\text { Non-covalent inter- } \\
\text { actions }\end{array}$ & $\begin{array}{l}\text { Non-viral vec- } \\
\text { tor delivered } \\
\text { efficiently to tumor } \\
\text { tissues }\end{array}$ & Du et al (2018) \\
\hline $\begin{array}{l}\text { PEG-PEI-GO-pDNA- } \\
\text { SiRNA }\end{array}$ & siRNA/pDNA & $\begin{array}{l}\text { Non-covalent inter- } \\
\text { actions }\end{array}$ & $\begin{array}{l}\text { Use photothermally } \\
\text { enhanced intracel- } \\
\text { lular trafficking of } \\
\text { nanocarriers for } \\
\text { light controllable } \\
\text { gene delivery }\end{array}$ & Liu et al. (2013a; b, c) \\
\hline
\end{tabular}

Therefore, the results solidly indicated that the modification of FA contributed to significantly improved tumor therapy (Fig. 4). Besides FA, other receptors such as cluster of differentiation-44 (CD44) (Nascimento et al. 2016; Mattheolabakis et al. 2015), HA (Song et al. 2014), Tf (Liu et al. 2015a, b) can also be used to further expand the targeting strategies of graphene oxide-based nanomaterials. Moreover, the subcellular organelles as a new targeted site for tumor therapy have attracted increasing attention. For example, Zhang et al. (2018) utilized glycyrrhetinic acid (GA), a mitochondrial targeting ligand, to modification of GO and loaded on DOX as carrier to targeted into mitochondria (Fig. 5). 
In addition to high-efficiency tumor targeting and accumulation, another key point is the controllable and complete drug release in effective tumor therapy. The stimuliresponsive nanomaterials are designed according to the unique characteristics of the tumor microenvironment. Endogenous stimuli usually include $\mathrm{pH}$ and redox, and exogenous stimuli usually include near-infrared (NIR) light and magnetic. These strategies can be used to promote the penetration, diffusion, and release of drugs. Wang et al. (2018) designed a galactosylated CS (GC) shell coated on GO surface for DOX delivery. Due to the pH-sensitive solubility of CS, CS-GO-DOX disaggregated in the acid tumor microenvironment, leading to expected antitumor therapeutic effect. Tran et al. (2018) synthesized mesoporous silica (MS) modified GO as a pH-responsive carrier for anticancer drug delivery. In the study, the $\mathrm{pH}$-sensitive of nanocomplexes were measured in phosphate buffer saline at $\mathrm{pH} 7.4$ and $\mathrm{pH}$ 5.5. The release fraction was $55.2 \%(\mathrm{pH}$ 7.4) and $69.0 \%$ (pH 5.5). Therefore, the $\mathrm{pH}$-responsive MS-GO can be used a successful strategy for smart drug delivery.

Due to the abnormal metabolism of tumor cells, the content of glutathione (GSH) in the microenvironment of tumor cells is much higher than that of normal cells or physiological environment (Han et al. 2016). Therefore, this abnormal GSH concentration in tumor can be used as an endogenous stimulus for drug release (Zhang et al. 2017a, b, c, d, e). Chen et al. (2014a, b, c) employed DOX-SS-nanographene oxide (NGO) to achieve the high-efficient redox-responsive drug delivery based on the GSH concentration in tumor. By the SERS and fluorescence signals, they found that DOX has higher release from DOX-SS-NGO at high GSH level $(\sim 60 \%)$ than at low GSH level $(\sim 10 \%)$. Therefore, the redox-responsive drug delivery system holds great promise in tumor therapy. Besides, magnetic-responsiveness (Thirunavukkarasu et al. 2018; Du et al. 2017) and NIR light-responsiveness (Yang et al. 2018; Jiang et al. 2018) have also been studied for realizing their antitumor effects.

Gene delivery Gene therapy as an ideal strategy for cancer treatment is widely investigated (Di Santo et al. 2019). However, gene therapy needs a vector that can protect genes from nuclease degradation and facilitate gene uptake with high transfection efficiency (Zhang et al. 2015a, b, c). Compared with viral vectors, non-viral gene carriers can avoid the limitations such as immune response, toxicity, chromosomal integration, mutagenesis, and high cost of production (Kim and Kim 2014; Guo and Huang 2012). Among

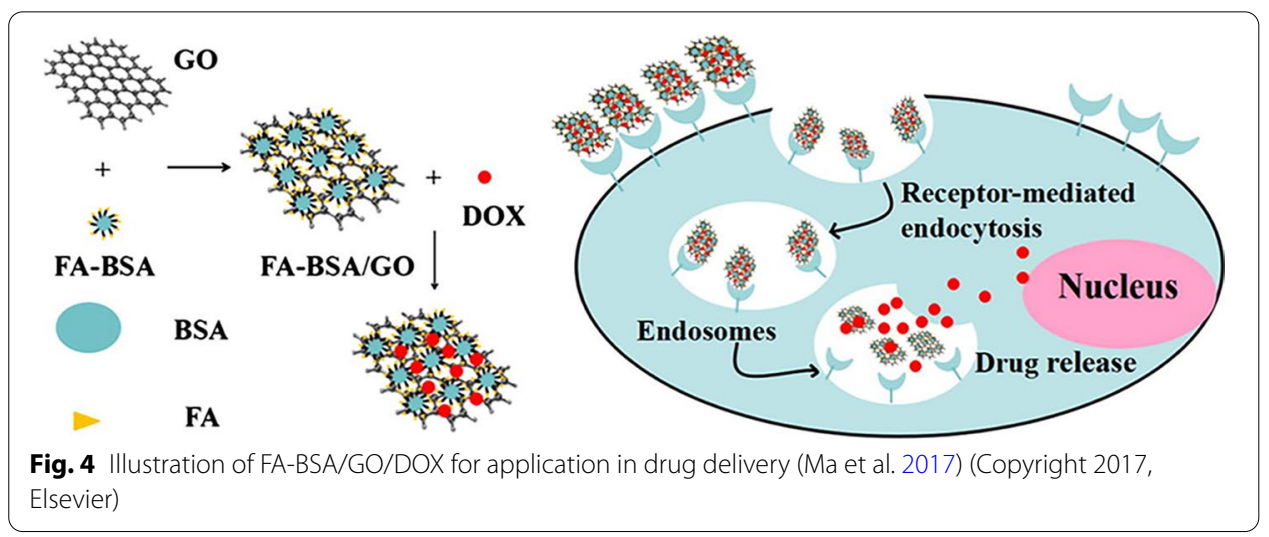


a
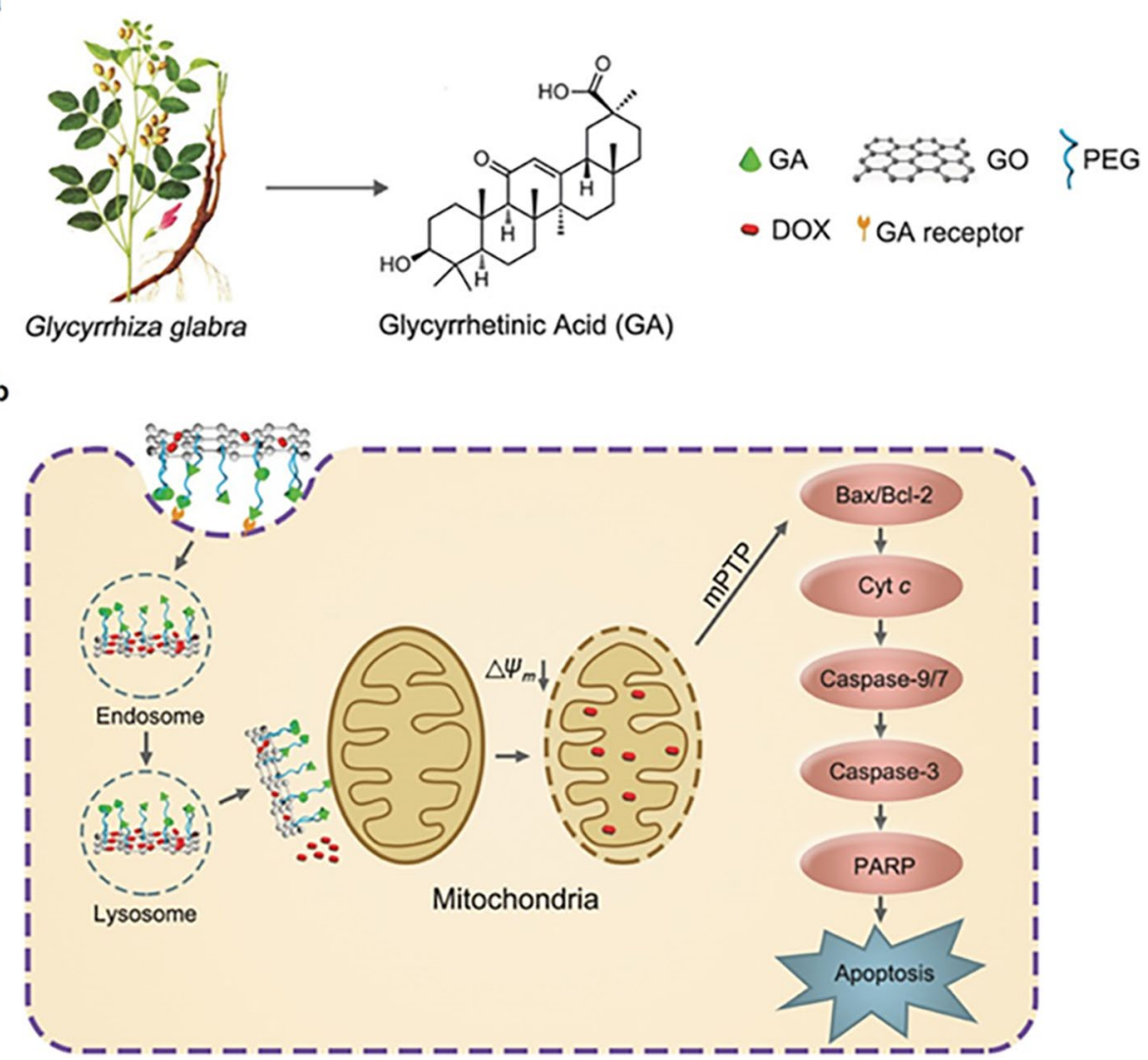

Fig. 5 Illustration of the combination of GA-GO@DOX nanocomposite as well as the mechanism of MMA pathway. a The natural product GA from Glycyrrhiza glabra was used. $\mathbf{b}$ The proposed mechanism of MMA pathway of GA-GO@DOX (Reproduced with permission (Zhang et al. 2018). Copyright 2018, WILEY-VCH)

various non-viral gene carriers for gene delivery, graphene oxide-based nanomaterials have been considered as the superior vehicles because of their good biocompatibility, biosafety, large surface area, adsorption capacity, and possesses negative charges. For instance, Lu et al. (2009) designed GO-based vector for gene delivery that could effectively adsorb single-stranded DNA (ssDNA). Pristine GO can absorb single-stranded DNA through $\pi-\pi$ stacking, but hard to load double-stranded DNA (dsDNA). To tackle this issue, Di Santo et al. (2019) designed nanoparticles composed of graphene oxide/ cationic lipid (GOCL) NPs and plasmid DNA (pDNA) to transfect human cervical cancer (HeLa) cells and human embryonic kidney (HEK-293) cells. Moreover, GO-based gene delivery system of RNAs is also widely studied. For instance, FA-conjugated chitosan oligosaccharide (FACO) functionalized $\mathrm{GO}\left(\mathrm{GO}-\mathrm{FACO}^{+}\right)$used for leading into DOX and small interfering RNA (siRNA) is designed to change drug resistance (Cao et al. 2013). Besides, Du et al. (2018) designed the PEG, PEI, and FA-modified GO for the targeted delivery of siRNA that can inhibit the growth of ovarian cancer cells, and the efficacy of such complex is evaluated by a series of in vitro experiments. To further improve the gene delivery efficiency and get a higher transfection effect, Liu et al. (2013a, b, c) designed a novel gene delivery carrier composed of PEG and PEI co-modified ultra-small nano-GO (NGO-PEG-PEI), a NIR-sensitive gene carrier, to load pDNA and siRNA. They demon- 
strated that the NGO-PEG-PEI could effectively regulate the expression or silence of the gene by the controllable NIR irradiation.

Graphene oxide-based nanomaterials have shown great advantages with high drug loading rate and controlled release-targeting efficiency due to the excellent properties including lateral dimensions, surface area, layer number, and surface chemistry (Singh et al. 2018; Hoseini-Ghahfarokhi et al. 2020; Muoz et al. 2019). Further functionalize its properties to achieve multifunctional drug delivery systems is a promising strategy for applying graphene oxide-based nanomaterials in clinics.

\section{Phototherapy}

Phototherapies, including photothermal therapy (PTT) and photodynamic therapy (PDT), are novel treatment methods for tumor ablation with various advantages such as remote controllability, spatiotemporal selectivity, and repeatability without cumulative toxicity (Sahu et al. 2013; Liu et al. 2015a, b; Shen et al. 2021). In this section, the discussion is not only focused on PTT and PDT of graphene oxide-based nanomaterials, but also covers photo-chemotherapy strategy as well as combined PTT and PDT strategy, as listed in Table 3.

Photothermal therapy The mechanism of PTT is the conversion of radiant light energy into local heat by external NIR laser irradiation, which leads to hyperthermia and elevates body temperature at the tumor site, thereby inducing damage and apoptosis of tumor cells (Yi et al. 2019; Mousavi et al. 2020). Since the light source is added to the specific part, it can kill tumor cells in the specific part without causing the death of normal cells (Li et al. 2015). Due to its specific delocalized electron arrangement, graphene oxidebased nanomaterials possess strong absorption in the NIR region, which can be used as promising photothermal sensitizers that can efficiently transfer photo energy to thermal energy (Yang et al. 2010). Furthermore, graphene oxide-based nanomaterials have better biocompatibility and lower cost for cancer therapy (Vila et al. 2014). Therefore, many researchers are committed to studying GO as a powerful PTT agent. For instance, Yang et al. (2015) synthesized a nanocomposite material, an aptamer-gold nanoparticle-

Table 3 Functionalized graphene oxide-based nanomaterials applied in combined anticancer therapy

\begin{tabular}{llll}
\hline $\begin{array}{l}\text { Type of combined } \\
\text { therapies }\end{array}$ & $\begin{array}{l}\text { Go-based } \\
\text { nanocomposites }\end{array}$ & Type of cancer & Ref. \\
\hline Chemo-PTT & NrGO-PEG/PEl & Breast & Li et al. (2016) \\
Chemo-PTT & PEG-NGO-C225/PEG & Gliomas & Yang et al. (2013a, b) \\
Chemo-PTT & NrGO-GNS@DOX & Breast & Wang et al. (2016) \\
Chemo-PDT & rGO-PVP-RGD & Gastric & Huang et al. (2015) \\
Chemo-PDT & RGO-TiO 2 & Liver & Shang et al. (2017) \\
PDT-PTT & mPEG-GO-C60 & Human cervical & Li et al. (2017) \\
PDT-PTT & GO-PF127-MB & Human cervical & Sahu et al. (2013) \\
PDT-PTT & rGO-PEG-Ru & Human lung & Zhang et al. (2017a, b, c, d, e) \\
Chemo-PDT-PTT & GO/(PEG-PpIX)/DOX & Breast/human cervical & Ting et al. (2018) \\
Chemo-PDT-PTT & LA-UCNPs@SiO $-C / H A @ ~$ & Liver & Chen et al. (2017a, b) \\
& mSiO $2-D O X @ N B$ & & \\
\hline
\end{tabular}


hybridized (Apt-AuNP-GO), that showed excellent breast cancer targeting and photothermal properties. Due to the existance of Mucin 1 (MUC1) aptamers, Apt-AuNPGO could specifically target to most breast cancer cells that overexpress MUC1. AuNPs anchored on GO can enhance the PTT effects by accelerating the deoxygenation of GO. Therefore, this nanocomposite showed both excellent tumors targeting and photothermal properties. Lim et al. (2018) presented the synthesis and biological applications of the $\mathrm{MnO}_{2}-\mathrm{FA}-\mathrm{GO}$ nanosheets. The proposed $\mathrm{MnO}_{2}-\mathrm{FA}-\mathrm{GO}$ nanosheet could be a powerful carrier for cancer targeting and PTT applications (Fig. 6). Besides, the light-heat effect of GO can be used to develop a light-responsive gene vector. By covalently binding PEG and PEI with GO, a light-controlled gene carrier (GO-PEG-PEI) was established, which improved the transfer efficiency of intracellular genes under laser irradiation without aggregation in serum (Feng et al. 2013).

Some literatures have reported that PTT is difficult to completely eradicate tumor cells due to the uneven heat distribution in tumor cells and the low capacity of light to penetrate the tumor, which leads to tumor recurrence (Tao et al. 2014). Therefore, the combination of chemotherapy and PTT as a new strategy to enhance the killing of cancer cells and prevent tumor recurrence has been proposed (Bao et al. 2016). This combination can not only increase the sensitivity of chemotherapy, but also improve the absorption of chemotherapy drugs in tumor cells or controls drug release (Dreaden et al. 2011). For instance, Li et al. (2016) designed a multifunctional nrGO-PEG/PEI/DOX nanocomposite to improve the therapeutic efficacy for tumors. In vitro and in vivo experiment results showed that the prepared nrGO-PEG/PEI/DOX nanocomposite exhibited remarkable anticancer effects in NIR laser irradiation. Besides, Yang et al. (2013a, b) synthesized a novel complex PEG-NGO-C225/EPI to targeting cancer cells. PEGylated NGO was used to carry anti-EGFR antibodies (C255) and epirubicin (EPI). C255 was used as a targeting molecule to combine with the over-expressed epidermal growth factor receptor (EGFR) in glioma cells so that the combination of chemotherapy and PTT could realize selective targeting therapy. In this study, U87 mouse xenograft model of glioma was used to research in vivo anticancer efficiency. PEG-NGO-C225/EPI had higher accumulation than PEG-NGO/EPI in tumor tissues. The mice exhibited complete tumor ablation within 10 days and had no tumor recurrence within 30 days. Mice in the control group that did not receive NIR light and treated only with EPI experienced a rapid tumor increase. The result showed that PEG-NGO-C225/EPI as a powerful targeting agent for the combination of chemotherapy and PTT that could inhibit the EGFR growth signal of cancer cells to prevent tumor growth and tumor recurrence effectively. In addition, chemo-PTT due to minimizing the side effects can act as an alternative treatment of breast cancer (Zare et al. 2018). Wang et al (2016) showed nanosized reduced graphene oxide (NRGO)-based combination therapy of chemo-PTT nanoplatform can be well used for treating metastatic breast cancer. In the study, by using bioluminescence to detect the signal of lung metastasis of $4 \mathrm{~T} 1$ breast cancer in mice, the mice treated with NRGO-based treatment nanoplatform have a weak BLI signal. The result indicated that NRGO-based treatment nanoplatform has good anti-metastatic efficacy.

Photodynamic therapy PDT as an effective cancer therapeutic method has been approved by Food and Drug Administration (FDA) (Qu et al. 2018), which exhibits many 


\section{a}

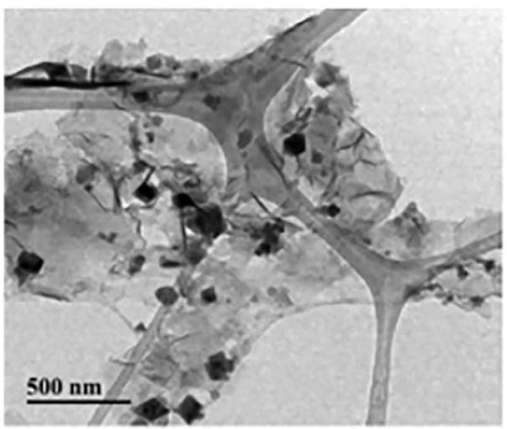

\section{$\mathrm{b}$ \\ Before NIR}

Fig. 6 Illustration of this composite $\mathrm{MnO}_{2}-\mathrm{FA}-\mathrm{GO}$ nanosheet in cancer targeting and PTT application. a TEM images of $\mathrm{MnO}_{2}-\mathrm{FA}-\mathrm{GO}$ nanosheets. b Analysis of PTT experiments employing the $\mathrm{MnO}_{2}-\mathrm{FA}-\mathrm{GO}$ nanosheets in HeLa cells. Scale bars are 100 um (Reproduced with permission (Lim et al. 2018). Copyright 2018, The Polymer Society of Korea and Springer)

merits such as specificity and repeated treatment (Zhang et al. 2015a, b, c). In PDT, photosensitizers (PSs) are needed to generate reactive oxygen species (ROSs) under specific light irradiation, X-ray, microwave (Chen and Zhang 2006; Yao et al. 2016; Zou et al. 2014; $\mathrm{Li}$ et al. 2010), which is essential to kill cancer cells. Moreover, PDT could damage the tumor vasculature and activate the immune response has been certified (Zhen et al. 2014; Yu et al. 2017). In recent years, PDT has been applied to the treatment of many cancers such as breast cancer (Hosseinzadeh et al. 2018), superficial bladder cancer (Jichlinski and Leisinger 2001), lung cancer (Chang et al. 2016), and cervical cancer (Wen et al. 2011; Muroya et al. 1996). Various PSs have been applied clinically or preclinically for PDT, including porphyrin, chlorin, or phthalocyanine derivatives, all of which have tetrapyrrole structures (Sharman et al. 1999; Li et al. 2020). However, owing to PSs being usually insoluble in aqueous solution, poor tumor selectivity, restricted absorption wavelength, and easily removed during blood circulation, PDT faces a huge challenge (Song et al. 2020). Therefore, to effectively deliver PSs to tumor cells or tumor sites is very important for achieving effective PDT (Poinard et al. 2018). Graphene oxide-based nanomaterials have been regarded as an ideal carrier of PSs benefiting from their large specific surface 
area, ultra-efficient fluorescence quenching ability, various surface functional groups (Shi et al. 2014). For example, Dong et al. (2010) designed a novel methoxy-polyethylene glycol (mPEG) modified NGO-mPEG as a carrier for PSs delivery. The carrier can significantly enhance the water solubility and biocompatibility of Ps, as well as the efficient cellular uptake by MCF-7 cells, which contribute to inhibition of MCF-7 cells via PDT. Moreover, Ding et al. (2016) reported that the application of GO-HA- $\mathrm{TiO}_{2}$ nanoparticles increases the ability to produce ROSs through mutual sensitization (Fig. 7). $\mathrm{TiO}_{2}$ and $\mathrm{HA}$ can combine to form a stable complex sensitive to $\mathrm{HA}$ to generate more ROSs. Meanwhile, $\mathrm{TiO}_{2}$ mounted on GO may also generate ROSs when exposed to visible light. In in vitro cell experiment results show that the PDT efficacy of $\mathrm{GO}-\mathrm{HA}-\mathrm{TiO}_{2}$ was greatly enhanced than that of HA-GO.

Chemotherapy is the most widely used method for the treatment of cancer. However, tumor cells utilize multiple mechanisms to reduce the accumulation of the drug at its intracellular site of action. Drug resistance is the major reason for the failure of chemotherapy. Overexpression of P-glycoprotein (P-gp), a drug efflux transporter, is an important determinant of tumor drug resistance. Recent studies indicate that P-gp-mediated drug resistance may be prevented by PDT (Trindade et al. 2000). Hence, the development of antitumor therapy with dual therapy of PDT and chemotherapy has been investigated to slow down multi-drug resistance and increase anticancer activity (Khdair et al. 2009). For example, Huang et al. (2015) designed the polyvinylpyrrolidone (PVP)-coated GO, which provides anchoring sites for ACDCRGDCFCG peptide (RGD4C). Through hydrophobic interactions and $\pi-\pi$ stacking, aromatic photosensitizer chlorin e6 ( $\mathrm{Ce} 6)$ can be effectively loaded into the rGO-PVP-RGD system. Compared with Ce6 alone, the nano-delivery system can significantly increase the accumulation of $\mathrm{Ce} 6$ in tumor cells and lead to an improved PDT efficacy. Moreover, Shang et al. (2017) reported the $\mathrm{TiO}_{2} \mathrm{NPs}$ conjugated with

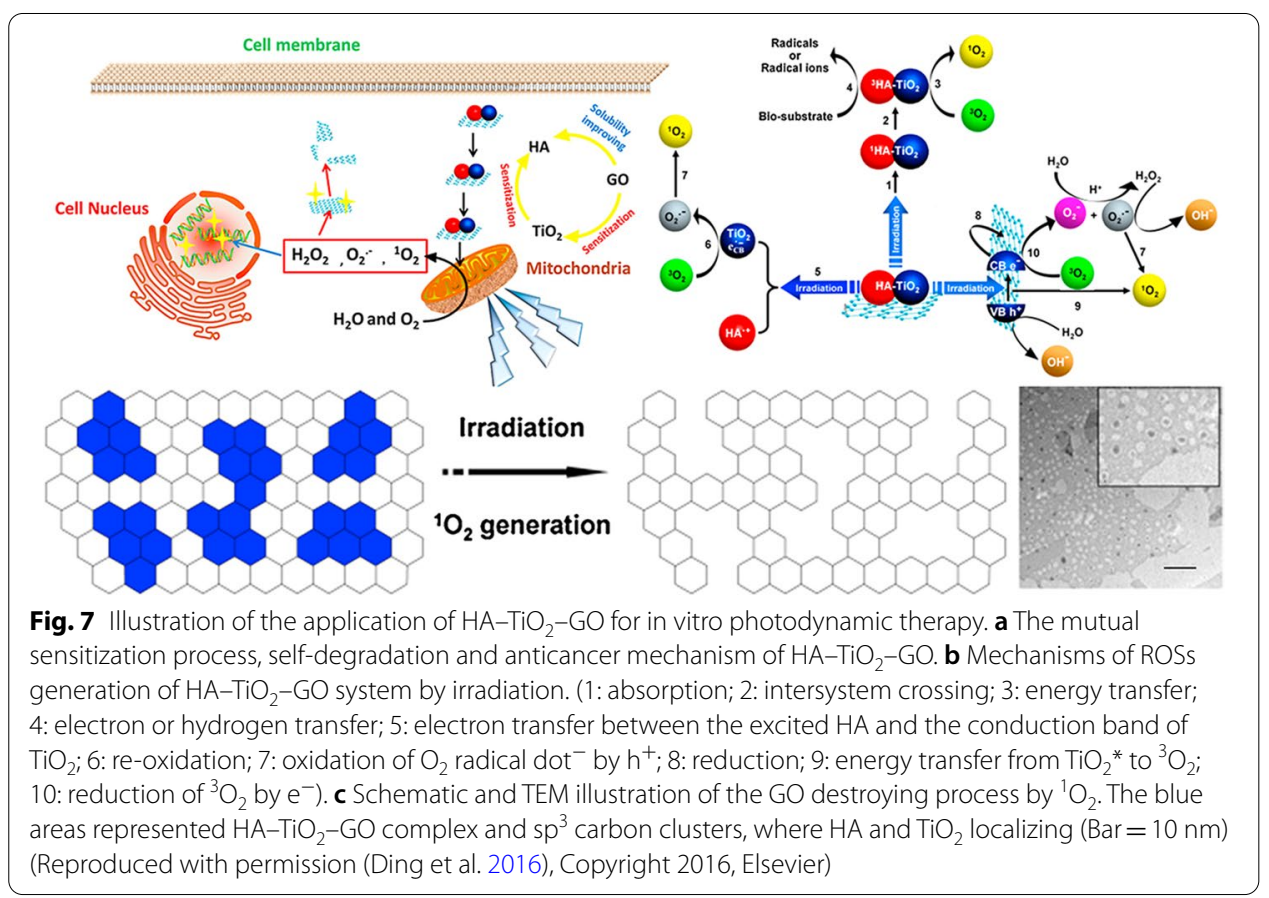


rGO-TiO ${ }_{2}$ composites for PDT. It is shown that $\mathrm{rGO}-\mathrm{TiO}_{2}$ composites can be used as an excellent PDT photosensitizer for tumor treatment.

Combined therapy of PDT and PTT PTT and PDT show very good antitumor effects, but there are still limitations that hinder their applications. For instance, PDT has poor cell uptake of PSs and a limited absorption wavelength below $600 \mathrm{~nm}$ (Guo et al. 2014). While PTT usually requires high-power density laser irradiation (Liu et al. 2014). To overcome the shortcomings of PTT and PDT, the development of combination therapies is of great significance. It has been reported that the PTT-PDT combination therapy shows a better therapeutic effect on tumors than the separate application of PTT/PDT (Wang et al. 2013; Zhang et al. 2015a, b, c). Graphene oxide-based nanomaterials can be used as both PS carrier and photothermal conversion agent, which can be investigated for combined PTT-PDT therapy. For example, Li et al. (2017) developed mPEG-GO-C ${ }_{60}$ complex as a multifunctional nano-platform, results showed that the combination of PDT/PTT can cause a significant synergistic therapeutic effect (Fig. 8). The prepared mPEG-GO-C 60 not only expand the absorption spectrum of photosensitizer $\mathrm{C}_{60}$ via conjugated effect, but also show no influence over the PTT effect of GO. When exposed under NIR light $\left(808 \mathrm{~nm}, 4 \mathrm{~W} / \mathrm{cm}^{2}\right)$ irradiation, $\mathrm{GO}-\mathrm{C}_{60}$ showed a significant temperature increase $(\Delta \mathrm{T})$ of $13^{\circ} \mathrm{C}$ in 9 min than distilled water $\left(1.6^{\circ} \mathrm{C}\right)$ and $\mathrm{C}_{61}(\mathrm{COONa})_{2}$ aqueous solution $\left(1.9^{\circ} \mathrm{C}\right)$, indicating the excellent PDT effect. At the same time, MTT was used to evaluate the antitumor ability of GO- $\mathrm{C}_{60}$ complex on Hela cells in vitro. It was shown that the dark cytotoxicity is not obvious without irradiation. When irradiated for $7 \mathrm{~min}$, the survival rate of HeLa cells incubated with $\mathrm{GO}-\mathrm{C}_{60}$ was the lowest $(58.52 \% \pm 4.65 \%)$. These results prove that $\mathrm{GO}-\mathrm{C}_{60}$ based PDT and PTT has a good synergistic effect and can be used for cancer treatment. Besides, Sahu et al. (2013) designed a PTT-PDT combination therapeutic agent of PF127-modified GO to deliver methylene blue (MB) and studied its anticancer performance. Through non-covalent bond, PLURONIC block copolymer was connected to nanographene oxide ( $\mathrm{nGO}$ ). The prepared $\mathrm{nGO}-\mathrm{MB}$ could high accumulate in the tumor region. In mouse normal fibroblast cell (NIH/3T3) and HeLa cells, nGO-MB can be easily absorbed and showed higher endocytosis. Combining the excellent PDT effect produced by $650 \mathrm{~nm}$ laser irradiation with laser-mediated heating at $808 \mathrm{~nm}$, a synergistic PTT/PDT of nGO-MB was obtained, which was more efficient than a single treatment method.

In addition, it has been reported that rGO-PEG-Ru could be applied for the combination of PTT and PDT in cancer treatment, which was composed of reduced nanographene oxide sheets and a phosphorescent polyethylene glycol-modified $\mathrm{Ru}$ complex (Zhang et al. 2017a, b, c, d, e). In this study, though cytotoxicity assay under $808 \mathrm{~nm}$ and $450 \mathrm{~nm}$ irradiation, the combined effects of PTT and PDT were evaluated. Meanwhile, the mechanism has shown that rGO-PEG-Ru can induce cell apoptosis by the generation of ROSs and cathepsin-initiated apoptotic signaling pathways under light irritation.

PTT and PDT are rapidly gaining importance owing to the noninvasiveness of light and the limited adverse effect associated with these treatments. However, most preclinical studies show that complete elimination of tumors is rarely observed. Combining PTT and PDT with chemotherapy or radiotherapy can further improve the therapeutic outcome and simultaneously decrease the side effects of conventional treatments 


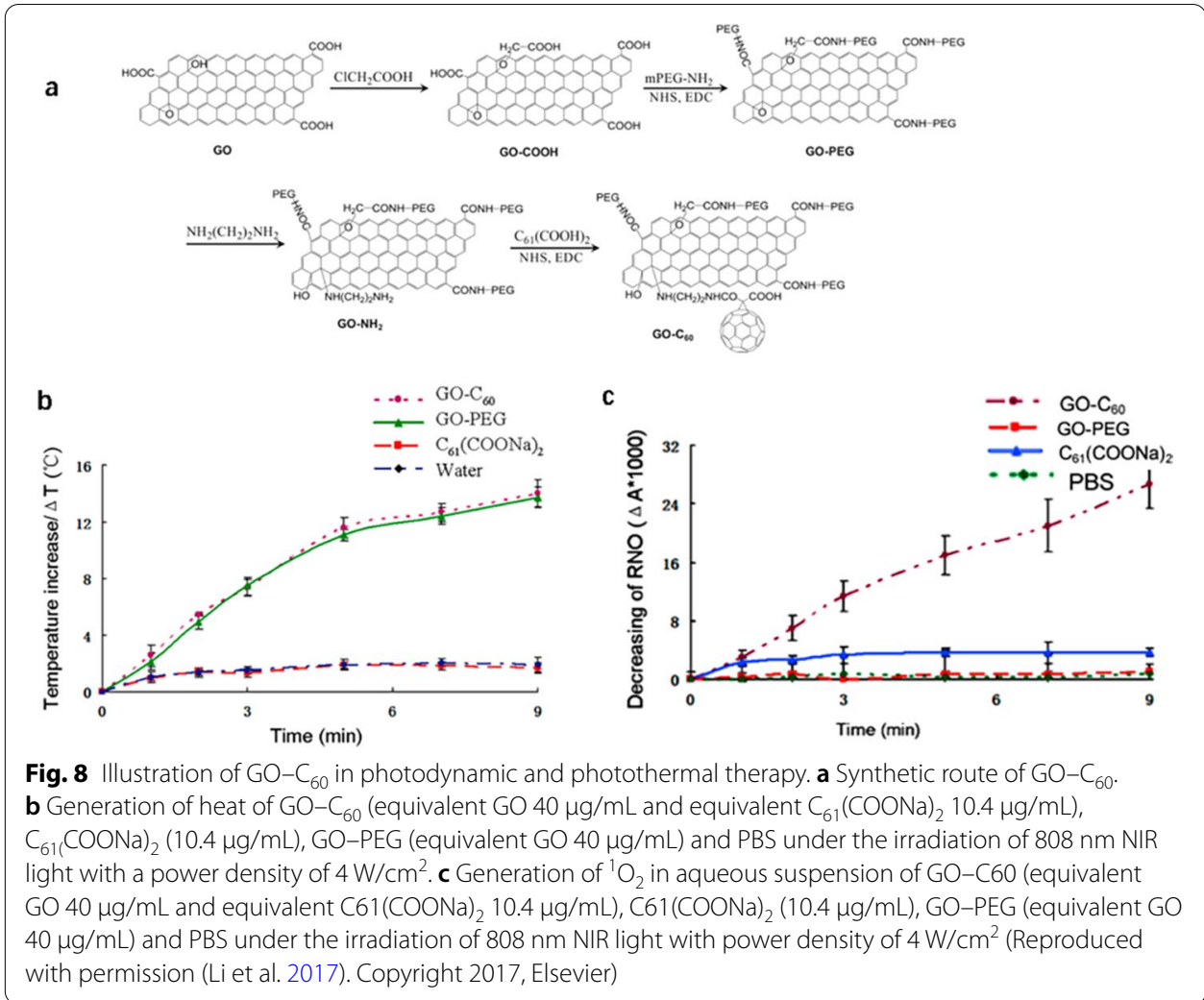

(Denkova et al. 2018). For example, Ting et al. (2018) reported a supramolecular hierarchical nanocomposite for the combination of PTT, PDT, and chemotherapy. The nanocomposite GO(PEG-PpIX) was prepared via supramolecular interactions, which is non-cytotoxic in the dark and phototoxic with light irradiation to exhibit efficient PTT and PDT effects. The drug loading content of the nanocomposite DOX/GO(PEG-PpIX) reaches $15.9 \%$ and the drug release shows a $\mathrm{pH}$-dependent profile. Chen et al. (2017a, b) strategically synthesized a core-shell-shell nanocomposite lactobionic acid (LA)up-conversion (UC) $\mathrm{NPs@SiO}{ }_{2}-\mathrm{C} / \mathrm{HA} @ \mathrm{mSiO}_{2}-\mathrm{DOX} @ O$-nitrobenzyl derivative linker (NB) for tumor therapy, which consists of UC core $\left(\mathrm{NaYF}_{4}: \mathrm{Yb}, \mathrm{Tm} @ \mathrm{NaYF}_{4}\right)$, silica sandwich shell (HA/C-Dots), and mesoporous silica outer-shell. This study demonstrated a NIR-sensitive nanoplatforms could enhance the cytotoxicity for tumor cells.

Above all, phototherapy based on graphene oxide-based nanomaterials is considered to be a promising method for cancer treatment due to multiple advantages like remote control, space-time selectivity, good repeatability and no cumulative toxicity (Durán et al. 2017; Guo and Mei 2014; Yi et al. 2019). Besides, graphene oxide-based nanomaterials can be designed to have synergistic efficacies that can not only generate heat under the NIR region but also act as excellent nanoplatforms to deliver PSs and drugs to tumors. Therefore, it is anticipated that in the near future, graphene oxide-based nanomaterials can be used as a treatment platform to combine PTT, PDT and chemotherapy to better play the role of tumor treatment. 


\section{Bioimaging}

Early detection and monitoring of carcinoma cells are important to prevent the progression of cancer. Biomedical imaging technologies as efficient tools for tumor diagnosis provide valuable guidance for tumor therapeutics. Graphene oxide-based nanomaterials have been extensively explored in various imaging techniques, including magnetic resonance imaging (MRI), fluorescence imaging (FLI) photoacoustic imaging (PAI), computed tomography (CT) (Li et al. 2013). In the following sections, we will discuss the current application of graphene oxide-based nanomaterials for bioimaging.

\section{Magnetic resonance imaging}

MRI is a non-invasive and non-ionizing diagnostic method with ultra-high spatial and temporal resolution (Gao et al. 2018; Song et al. 2018a, b). The location, size, and boundary of pathological areas such as tumors can be observed (Xu et al. 2012). To provide detailed and accurate imaging information, contrast agents (CAs) should accumulate in the tumor region, such as Gd, Mn, and Fe (Cong et al. 2010). Developing a vector with specific tumor targeting and prolonging blood circulation time is an urgent issue to be solved. Paramagnetic metals functionalized graphene oxide-based nanomaterials are suitable for MRI. For example, Cong et al. (2010) designed $\mathrm{Fe}_{3} \mathrm{O}_{4}$ decorated poly (4-styrene sulfonate)-GO for MRI application by the high-temperature thermal decomposition method. The prepared functional GO exhibited good water solubility and excellent MRI effect. Zhang et al. (2013) report on the development of a two-dimensional nanomaterial GO-based $T_{1}$ MRI CA. Compared with gadolinium diethylene triamine pentaacetate (Gd-DTPA), gadolinium-functionalized nanographene oxide (Gd-NGO) showed a much higher $T_{1}$ relaxivity value $\left(r_{1}\right)$ and contrast of in vivo $T_{1}$-weighted MRI. Moreover, Peng et al. (2012) developed a $\mathrm{MnFe}_{2} \mathrm{O}_{4}$ nanoparticle decorated-GO for $T_{2}$ weighted MRI, which got a high $T_{2}$ relaxivity value $\left(r_{2}\right)$ of $256.2(\mathrm{mM})^{-1} \mathrm{~s}^{-1}$.

The combination of MRI and PTT is of great significance to realize simultaneous diagnosis and treatment. For instance, Meng et al. (2017) prepared nanoscaled metalorganic frames (NMOFs) composited GO and used it in tumor-guided PTT with MRI. Results revealed that the fabricated NMOFs/GO was effective in imaging-guided PTT for clinical antitumor applications. $T_{1}$-weighted MRI-guided PTT was also adopted for tumor therapy (Zhang et al. 2015a, b, c). The author designed a $\mathrm{BaGdF}_{5}$ and PEG-modified GO, which exhibited excellent $T_{1}$-weighted imaging and photothermal conversion performance. According to the obvious contrast between tumor tissue and normal tissue on the MRI, the location and size of the tumor can be clearly obtained. Then, the tumor area of the mice treated with $\mathrm{GO} / \mathrm{BaGdF} 5 / \mathrm{PEG}$ was irradiated by a near-infrared laser to produced significant heating to achieve the antitumor effect.

\section{Fluorescence imaging}

FLI is a non-invasive technique based on photons emitted by fluorescent probes (Baker and Baker 2010; Zhu et al. 2013; Tang et al. 2020; Xu et al. 2020) and is often used to monitor the pathological tissue and trace the distribution and metabolism of drugs during the therapeutic process (He et al. 2018). This method holds some advantages, including negligible damage to normal tissue, rapid response, strong imaging contrast, and 
ultrahigh sensitivity. Hence, it can be used as a promising technology for tumor diagnosis and therapy (Menon et al. 2013).

Due to the superhigh pay-load ability of GO, FL agents with high-efficiency imaging performance are labeled on the GO platform to introduce FLI-guided theranostic (Ocsoy et al. 2016). Based on the intrinsic photoluminescence (PL) of nGO in the visible and infrared regions, Sun et al. (2008) developed a covalently conjugated B-cell-specific antibody Rituxan (anti-CD20) to PEG-modified NGO to selectively recognize and bind to B-cell lymphoma cells. However, the fluorescence quantum yield (QY) of the NGOPEG-CD20 was difficult to quantify, which limits its application. Therefore, organic fluorescent dyes are used to functionalize graphene oxide-based nanomaterials for FL imaging. For example, Yang et al. (2010) synthesized Cy7, a NIR dye, modified nanographene oxide sheet (nGO)-PEG (nGO-PEG-Cy7) hybrid for in vivo FL imaging of tumor xenografted mice, which showed high tumor accumulation due to the enhanced permeability and retention (EPR) effect of cancerous tumors.

Besides, FL imaging guide PTT was also exploited (Fig. 9) (Chen et al. 2016). Cypate was covalently linked with PEGylated GO (GO-Cypate) by amide reaction. The prepared GO-Cypate showed excellent FL imaging and enhanced PTT effect. Huang et al. (2013) strategically designed a photo-theranostic agent based on Ce6 photosensitizer conjugated silica-coated gold nanoclusters (AuNCs@SiO $2-\mathrm{Ce} 6$ ) for FL imaging-guided PDT. In this work, the complex offered a remarkably improved photodynamic therapeutic efficacy compared to free Ce6.

\section{Photoacoustic imaging}

PAI is a powerful diagnostic tool based on the photoacoustic (PA) effect, in which the absorbed short pulses of non-ionizing laser pulses are converted into heat, resulting in specific acoustic signals emission due to thermal expansion (Huang et al. 2013). Since PAI can provide optical absorption contrast and high resolution, it is more suitable for deep tissue/organ imaging. PA agents usually need to perform excellent photothermal conversion efficiency (Bai et al. 2015). Therefore, PAI agents including noble metal (e. g. Au NPs), inorganic NPs (e. g. GO), semiconducting NPs, and NIR dyes (e. g. indocyanine green) are the most used (Hu et al. 2016; Liu et al. 2019). In graphene oxidebased nanomaterials, rGO can act as a PA contrast agent and suitable carrier, since rGO with a larger $\mathrm{sp}^{2}$ domain than GO, has strong optical absorbance in the NIR region (Lalwani et al. 2013). Moon et al. (2015) have developed rGO-gold nanorods (Au NRs) for enhanced PA and PTT of the tumor. Specifically, the combination of Au NRs with GO could efficiently transfer heat energy and induce amplified PA signal (as high as 40-fold). Results of in vivo experiment showed that PA images have high spatial resolution and low background noise and can provide important pathological information for the following therapeutic period. Therefore, the prepared rGO-Au demonstrated great promises in clinical applications for sensitive PAI-guided tumor therapy.

\section{Raman imaging}

In biomolecular detection and disease diagnosis, surface-enhanced Raman scattering (SERS) is widely used due to non-invasive, ultra-sensitive, and high spatial resolution (Song et al. 2018a, b). Noble metals with specific local surface plasmon resonance (LSPR) 


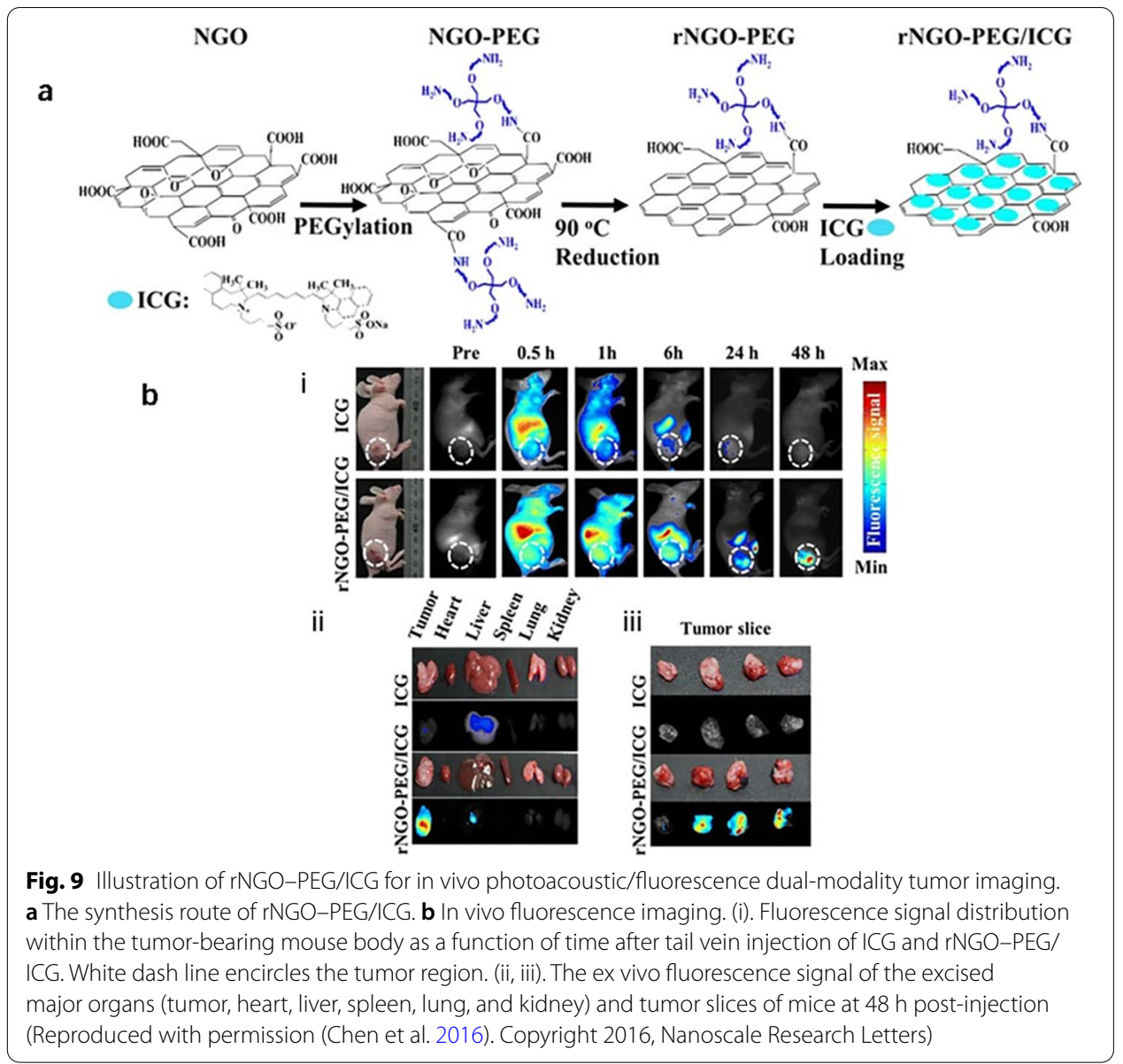

characteristics, such as gold, exhibit excellent SERS activity (Song et al. 2016). In recent years, hybrid graphene oxide nanoparticles have been developed to improve the optical properties of GO, which facilitates the application of GO in the SERS. Compared with using precious metals alone, the hybrid nanoparticles can significantly enhance the SERS signal through the specific electrostatic interaction between metals and the strong electromagnetic field mediated by plasma coupling in the cavity (Song et al. 2016). Liu et al. (2013a; b, c) reported the application of silver-GO-based SERS probe (FA-GO-AgNPs) induced cancer cell detection. In this report, the author utilized the FA-GO-AgNPs to achieve high-sensitive SERS signal. Besides, Zhang et al. (2016) designed a multifunctional platform of GO (GO/AuNP/FA) to targeted Raman imaging of HeLa cells. In this study, Raman imaging was realized employing the SERS effect of the AuNPs. To get a high-efficiency SERS imaging, Moon et al. (2015) also designed GONS for cancer cell imaging. By using GONS, which achieved ultra-sensitive SERS signal.

\section{Computed tomography}

$\mathrm{CT}$ is a widely adopted disease diagnosis method in the clinic, which is of non-invasive, high spatial resolution (Lin et al. 2017). Nanomaterials containing electron-dense elements with high atomic number have been proposed as CT agents, which usually has 
$\mathrm{X}$-ray attenuation capability, and contributes to the ultra-high contrast of CT signals, including $\mathrm{Au}, \mathrm{Bi}$, and Gd, (Lee et al. 2013). Dou et al. (2016) designed PVP-rGO/Bi $\mathrm{S}_{3}$ for imaging-guided cancer therapy (Fig. 10). The prepared PVP-rGO/Bi $\mathrm{S}_{3}$ showed excellent CT performance, and the position and definition of the tumor can be clearly observed. Shi et al. (2014) prepared GO@Ag nanocomposites by chemical deposition of Ag nanoparticles onto GO through a hydrothermal reaction. DOX as the model drug was employed and linked to GO@Ag via ester bonds. The prepared GO@Ag-DOX-NGR showed excellent chem-photothermal therapeutic efficacy, tumor-targeting property, NIR laser-controlled drug releasing function, and X-ray imaging ability.

Recently, there have been a lot of achievements in using graphene oxide-based nanomaterials for in vitro cellular and in vivo bioimaging. Nevertheless, the application of graphene oxide-based nanomaterials in bioimaging is still in the infancy, and there are many clinical uncertainties, such as potential toxicity, which may limit its in vivo application. However, in bioimaging for tumor diagnosis, graphene oxide-based nanomaterials have more advantages than other materials. For example, it can play the multiple roles: (1) as CAs due to their intrinsic FL emission, Raman scattering, and NIR absorbance; (2) as carriers; (3) as fluorescence quenchers; (4) as wrapping materials; (5) as building blocks, which promotes researchers to further explore to break through the

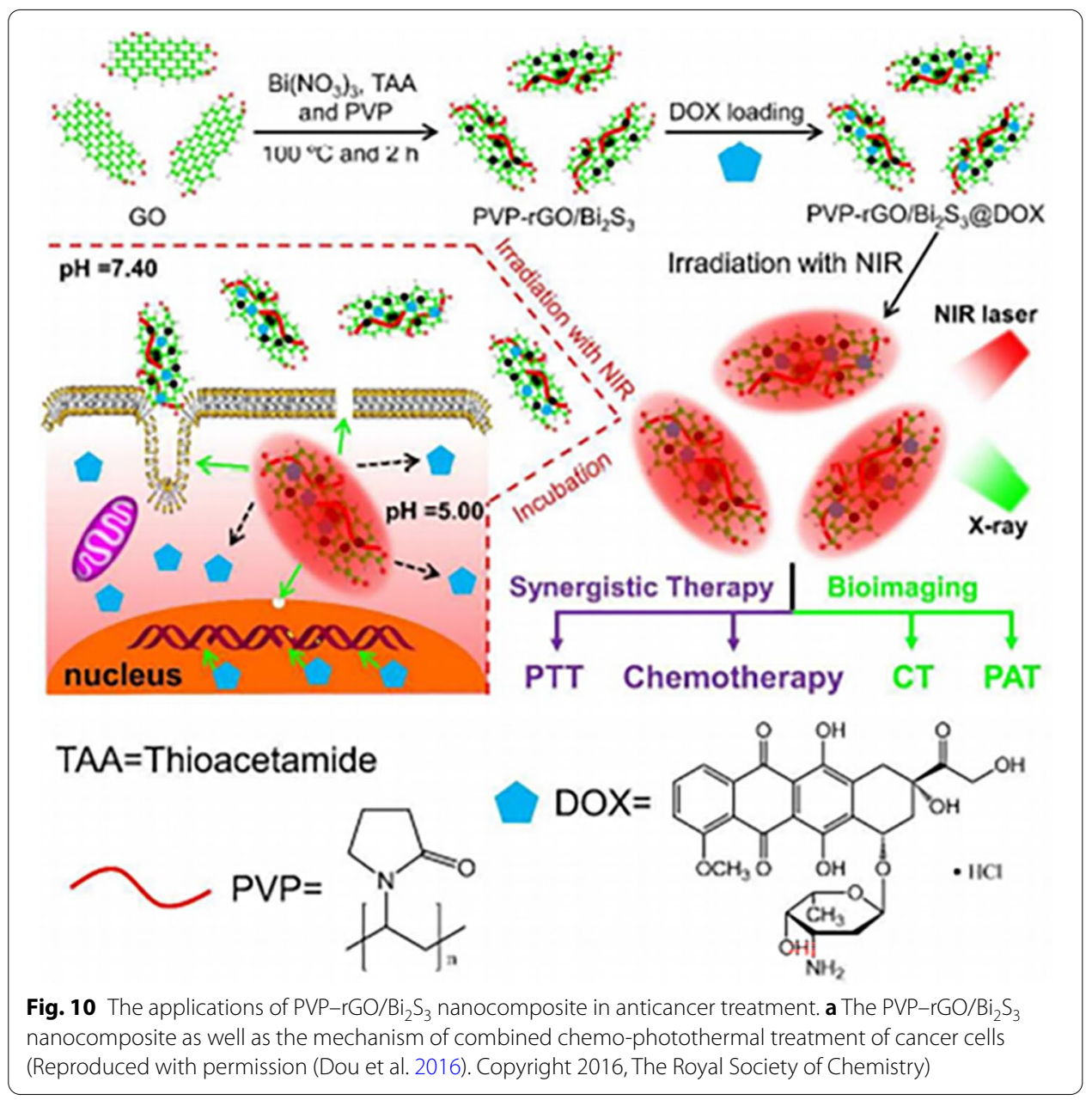


defects. Graphene oxide-based nanomaterials exhibited excellent PA/MR/CT/FL multimodel bioimaging performance, which could not only detect and characterize diseases, but also rapidly monitor the tumor treatment response. Therefore, more attentions have been aroused into the research of graphene oxide to overcome the limitation of in vivo application. The design of multi-model bioimaging of graphene oxide-based nanomaterials is one of the promising strategies by making full use of the advantages of different imaging modes and avoid their shortcomings-low sensitivity, long response time, poor resolution and tissue penetration, and side effect, to provide significantly improved imaging quality for accurate diagnosis and image-guided treatment of tumors.

\section{Biosafety}

It is crucial to study the biosafety of graphene oxide-based nanomaterials in vitro and in vivo to determine whether they can be used as clinical candidates. So far, extensive studies have been illustrated the biotoxicity, immunological compatibility, immunological compatibility, and inflammatory responses of graphene oxide-based nanomaterials.

\section{Biotoxicity}

Graphene oxide-based nanomaterials show great potentials in cancer treatment due to outstanding properties such as surface properties, photothermal property, and $\mathrm{pH}$ sensitivity. However, researchers need to consider their biotoxicity as one of the primary issues (Wang et al. 2011). Most researches have indicated that the biological toxicity of graphene oxide mainly comes from its surface properties: charge, oxygen content, surface structure, lateral dimension, and corona effect. (Guo et al. 2014). Besides, other factors are involved in influencing biotoxicity: cell types, concentration, and detection methods (Gautam et al. Miyanda and Gautam, 2017).

It has been proven that graphene oxide-based nanocomposites show toxicity effects to both prokaryotic and eukaryotic cells. For toxicity to eukaryotic cells, numbers of mechanisms have been proposed, such as DNA and mitochondrial damage (Liu et al. 2013a, b, c), inflammatory responses (Orecchioni et al. 2016), autophagy (Huang et al. 2015), necrosis (Qu et al. 2013), and apoptosis (Li et al. 2012a, b). For toxicity to prokaryotic cells, Zou et al. (2016) summarized the mechanisms of the antimicrobial activities of graphene oxide-based nanomaterials, such as encapsulate and capture bacterial membranes. Furthermore, results of in vitro and in vivo experiments have shown that GO had obvious dose-dependent toxicity. In studying the toxicity of GO in mice, it was found that low-dose $(0.1 \mathrm{mg})$ and medium-dose $(0.25 \mathrm{mg}) \mathrm{GO}$ had almost no effect on mice. While when the dose reached $4 \mathrm{mg}$, it showed liver and lung damage (Wang et al. 2011). In addition, chromosomal aberrations and DNA damage induced by GO were also found (Durán et al. 2017).

\section{Hemocompatibility}

Hemocompatibility investigation is an important toxicity assessment of GO (Kiew et al. 2016). In general, fresh blood collected from healthy animals is applied for hemolytic analysis to evaluate hemocompatibility. The hemolytic properties of GO were usually caused due to the electrostatic interaction between the GO and membrane of red blood cell (RBC). However, proper surface modifications could improve the hemocompatibility 
of GO. For example, by adopting CS, the hemolytic activity of GO can be significantly eliminated (Wu et al. 2015).

\section{Immunological compatibility}

Immunological compatibility of GO is also considered as a factor of biosafety. It has been reported that the presence of GO could cause strong immunogenicity proved by a remarkable increase of tumor necrosis factor alpha (TNF- $\alpha$ ), interleukin-1 (IL-1), and interleukin-6 (IL-6) (Zhi et al. 2013). Meanwhile, PVP-modified GO possesses better immunological compatibility.

\section{Inflammatory responses}

When macrophages play the role of unconventional immune defense, GO can be eliminated or cause inflammation before reaching the target. Yue et al. (2012) found that IL-6, TNF- $\alpha$, monocyte chemotactic protein 1 (MCP-1), interleukin-12 (IL-12), and interferon $\gamma($ IFN- $\gamma$ ) can be increased significantly in the presence of GO, leading to serious inflammatory responses. Ma et al. (2015) reported GO can induce more inflammatory cytokines by interacting with toll-like receptors to activate the NF-kappaB (NF-kB) pathway. Meanwhile, some studies showed that functionalized NGOs could avoid inflammatory responses by macrophages via weakening the opsonin-protein interaction (Kiew et al. 2016).

\section{Conclusion}

This review aims to investigate the applications of graphene oxide-based nanomaterials (e.g., GO and rGO) in cancer therapy including drug/gene delivery, phototherapy, bioimaging. In terms of drug and gene delivery, compared with other drug delivery systems, graphene oxide-based nanomaterials can obviously display high drug loading rate, targeting effect, increasing the sensitivity of chemotherapy drugs/genes. For the application of phototherapy, the combination of graphene oxide-based nanomaterials with PTT to achieve tumor elimination through the photothermal effect of GO. PDT based on graphene oxide-based nanomaterials can increase the water solubility of hydrophobic PSs and selectively deliver PS to cancer cells via the EPR effect. Meanwhile, the therapeutic diagnosis platform assembled by graphene oxide-based nanomaterials is applied to the early diagnosis and treatment of cancer. Besides, to obtain the best cancer treatment effect, new treatment strategies have been proposed such as PTT-PDT, chemo-PTT, and chemo-PDT.

A review of current literature has revealed the majority of present studies demonstrate that graphene oxide-based nanomaterials hold a bright future in nanomedicine. This review not only summarizes the excellent achievements in the last decades, but also pays particular attentions to the latest achievements in 2 years. Moreover, this review represents a comprehensive summary of all the aspects of applying graphene oxidebased nanomaterials in cancer treatment. Overall, this review can help readers achieve comprehensive understanding of the application of graphene oxide-based nanomaterials in tumor treatment and grasp the latest research achievements, thus inspiring novel research ideas and making contribution to the research field of graphene oxide-based nanomaterials for antitumor therapy. Unfortunately, there still exist some requirements 
to address the remaining challenges. One of the concerns for the challenge is the toxicity of graphene oxide-based nanomaterials. Although a large number of studies have been conducted to confirm the in vitro and in vivo toxicity of graphene oxide-based nanomaterials and its derivatives, the potential nanotoxicity requires further in-depth investigations. For in vitro toxicity, it is very important to understand its mechanism, especially the cellular uptake mechanism of graphene oxide-based nanomaterials. For in vivo toxicity, it is necessary to study the absorption, distribution, metabolism, and excretion in vivo. Furthermore, how to properly design graphene oxide-based nanomaterials to achieve the desired therapeutic effect is a critical issue. On the one hand, to diagnose and treat tumors, drugs or other functional agents need to be successfully delivered to tumor tissues and retained for a long time. Graphene oxide-based nanomaterials need to be designed to a suitable size to avoid the endoplasmic reticulation of large-size nanomaterials and the rapid clearance of ultra-small nanomaterials and to effectively passively target the tumor site. On the other hand, according to the receptors overexpressed on the tumor cell membrane to ensure the effective accumulation and retention of graphene oxide-based nanomaterials in the tumor. Endogenous and exogenous stimuli should also be fully utilized to realize the intelligent regulation of tumor nanoplatforms. Besides, many shortcomings in the design of graphene oxide-based nanomaterials as the multifunctional platform should be avoided, including complex design, cumbersome synthesis, low integration efficiency, lack of synergy, and uncertain biological responses.

In conclusion, graphene oxide-based nanomaterials have brought many surprises and challenges. In the near future graphene oxide-based nanomaterials will arouse ultimate benefits for human diseases treatment, especially for cancer treatment.

\begin{abstract}
Abbreviations
A549cells: Lung adenocarcinoma cells; AgNPs: Silver nanoparticles; AuNPs: Gold nanoparticles; anti-CD20: Rituxan; BSA: Bovine serum albumin; B-rGO: Bacterially reduced graphene oxide; Ce6: Chlorin e6; CD-44: Cluster of differentiation-44; CS: Chitosan; CT: Computed tomography; CAs: Contrast agents; CPT: Camptothecin; C255: Anti-EGFR antibodies; CAMR: Cell attach molecular receptor; DEX: Dextran; DNA: Deoxyribonucleic acid; DOX: Doxorubicin hydrochloride; EPI: Epirubicin; EGFR: Epidermal growth factor receptor; EPR: Enhance permeability and retention; FACO: Folic acidconjugated chitosan oligosaccharide; $\mathrm{FACO}^{+}$: Folic acid-conjugated chitosan oligosaccharide containing quaternary ammonium groups; FLimaging: Fluorescence imaging; FDA: Food and Drug Administration; FGO: Fluorinated graphene oxide; GC: Galactosylated chitosan; NGR: AsnGly-Arg; GA: Glycyrrhetinic acid; GONS: GO-nanoshells; GSH: Glutathione; GO: Graphene oxide; GOCL: Graphene oxide/cationic lipid; HA: Hypocrellin A; HCC: Human hepatocellular carcinoma; HepG2cells: Human liver cancer cells; HeLacells: Human cervical cancer cells; HEK-293: Human embryonic kidney; HA: Hyaluronic acid; $I_{50}$ : Half-maximum inhibitory concentration; ICG: Indocyanine green; IL-1: Interleukin-1; IL-6: Interleukin-6; L-12: Interleukin-12; IFN-ץ: Interferon Y; LA: Lactobionic acid; LSPR: Local surface plasmon resonance; mPEG: Methoxypolyethylene glycol; MS: Mesoporous silica; MRI: Magnetic resonance imaging; MDR: Multiple drug resistance; MB: Methylene blue; MCP-1: Monocyte chemotactic protein 1; NB: O-Nitrobenzyl derivative linker; NIR: Near infrared; NF-kB: NF-kappaB; NGO: Nanographene oxide; nGO: Nanographene oxide sheet; NPs: Nanoparticles; NMOFs: Nanoscale metal-organic frames; NIH/3T3: Mouse normal fibroblast cell; PL: Photoluminescence; PEG: Polyethylene glycol; PLL: Poly-L-lysine; PpIX: Protoporphyrin IX; PVA: Poly-vinylalcohol; PF127: Pluronic F127; PEl: Poly-ethylenimine; PAA: Polyacrylic acid; PTX: Paclitaxel; pDNA: Plasmid DNA; PTT: Photothermal therapy; PDT: Photodynamic therapy; PSs: Photosensitizers; P-gp: P-glycoprotein; PVP: Polyvinylpyrrolidone; PAl: Photoacoustic imaging; PA: Photoacoustic; QY: Fluorescence quantum yield; $r G O$ : Reduced graphene oxide; $r_{1}: T_{1}$ Relaxivity value; $r_{2}: T_{2}$ Relaxivity value; ROSs: Reactive oxygen species; RGD4C: ACDCRGDCFCG peptide; RBC: Red blood cell; RNA: Ribonucleic acid; SERS: Surface-enhanced Raman scattering; ssDNA: Single-stranded DNA; siRNA: Small interfering RNA; SA: Sodium alginate; SN38: 7-Ethyl-10-hydroxycamptothecin; Tf: Transferrin; TNF-a: Tumor necrosis factor alpha; UC: Up-conversion; VEGFR: Vascular endothelial growth factor receptor; -OH: Hydroxyl; -O-: Epoxide; -COOH: Carboxylic acid.
\end{abstract}

\title{
Acknowledgements
}

None.

\section{Authors' contributions}

Conception/design: LL and QM. Collection and/or assembly of data: LL, QM, YG, JC, SH, YL and TZ. Manuscript writing: LL, QM and Yang Song. Final approval of manuscript: QM, JC, Yang Song and Yong Sun. All authors read and approved the final manuscript. 


\section{Funding}

This study was supported by the National Natural Science Foundation of China [22008130], the China Postdoctoral Science Foundation (2020M682124), Qingdao Postdoctoral Researchers Applied Research Project Foundation (RZ2000001426), Scientific Research Foundation for Youth Scholars from Qingdao University (DC1900014265), the Major Science and Technology Innovation Projects of Shandong Province [2018CXGC1408], the Science and Technology Projects for people's livelihood of Qingdao [18-6-1-93-nsh].

\section{Availability of data and materials}

The datasets used and/or analyzed during the current study are available from the corresponding author on reasonable request.

\section{Declarations}

Ethics approval and consent to participate

Not applicable.

\section{Consent for publication}

Current study is available from the corresponding author on reasonable request.

\section{Competing interests}

All of the authors declare that they have no competing interests.

\section{Author details}

${ }^{1}$ Department of Pharmaceutics, School of Pharmacy, Qingdao University, Qingdao 266071, China. ${ }^{2}$ State Key Laboratory of Metal Matrix Composites, School of Material Science and Engineering, Shanghai Jiao Tong University, Shanghai, China.

Received: 24 February 2021 Accepted: 29 June 2021

Published online: 12 July 2021

\section{References}

Abed S, Bakhsheshi-Rad HR, Yaghoubi H, Ning L, Chen X. Antibacterial activities of zeolite/silver-graphene oxide nanocomposite in bone implants. Mater Technol. 2020. https://doi.org/10.1080/10667857.2020.1786784.

Aliabadi M, Shagholani H, Yunessnia Lehi A. Synthesis of a novel biocompatible nanocomposite of graphene oxide and magnetic nanoparticles for drug delivery. Int J Biol Macromol. 2017;98:287-91. https://doi.org/10.1016/j.ijbiomac. 2017.02.012.

Alibolandi M, Mohammadi M, Taghdisi SM, Ramezani M, Abnous K. Fabrication of aptamer decorated dextran coated nano-graphene oxide for targeted drug delivery. Carbohydr Polym. 2017;155:218-29. https://doi.org/10.1016/j. carbpol.2016.08.046.

Bai H, Li C, Shi G. Functional composite materials based on chemically converted graphene. Adv Mater. 2011;23(9):1089115. https://doi.org/10.1002/adma.201003753.

Bai LY, Yang XQ, An J, Zhang L, Zhao K, Qin MY, Fang BY, Li C, Xuan Y, Zhang XS, Zhao YD, Ma ZY. Multifunctional magnetic-hollow gold nanospheres for bimodal cancer cell imaging and photothermal therapy. Nanotechnology. 2015;26(31): 315701. https://doi.org/10.1088/0957-4484/26/31/315701.

Baker SN, Baker GA. Luminescent carbon nanodots: emergent nanolights. Angew Chem. 2010;49(38):6726-44. https:// doi.org/10.1002/anie.200906623 (International ed. in English).

Bao T, Yin W, Zheng X, Zhang X, Yu J, Dong X, Yong Y, Gao F, Yan L, Gu Z, Zhao Y. One-pot synthesis of PEGylated plasmonic $\mathrm{MoO}(3-\mathrm{x})$ hollow nanospheres for photoacoustic imaging guided chemo-photothermal combinational therapy of cancer. Biomaterials. 2016;76:11-24. https://doi.org/10.1016/j.biomaterials.2015.10.048.

Brodie BC. On the atomic weight of graphite. Proc R Soc Lond. 1859:10:11-2. https://doi.org/10.1098/rspl.1859.0007.

Byun $\mathrm{E}$, Lee H. Enhanced loading efficiency and sustained release of doxorubicin from hyaluronic acid/graphene oxide composite hydrogels by a mussel-inspired catecholamine. J Nanosci Nanotechnol. 2014;14(10):7395-401. https:// doi.org/10.1166/jnn.2014.9571

Cao $X$, Feng F, Wang $Y$, Yang X, Duan H, Chen Y. Folic acid-conjugated graphene oxide as a transporter of chemotherapeutic drug and sirna for reversal of cancer drug resistance. J Nanopart Res. 2013;15(10):1965. https://doi.org/10 1007/s11051-013-1965-y.

Cao L, Zhang F, Wang Q, Wu X. Fabrication of chitosan/graphene oxide polymer nanofiber and its biocompatibility for cartilage tissue engineering. Mater Sci Eng C Mater Biol Appl. 2017;79:697-701. https://doi.org/10.1016/j.msec. 2017.05.056.

Chang JE, Cho HJ, Jheon S. Anticancer efficacy of photodynamic therapy with lung cancer-targeted nanoparticles. J vis Exp. 2016;118:54865. https://doi.org/10.3791/54865.

Chen W, Zhang J. Using nanoparticles to enable simultaneous radiation and photodynamic therapies for cancer treatment. J Nanosci Nanotechnol. 2006;6(4):1159-66. https://doi.org/10.1166/jnn.2006.327.

Chen JT, Fu YJ, An QF, Lo SC, Huang SH, Hung WS, Hu CC, Lee KR, Lai JY. Tuning nanostructure of graphene oxide/polyelectrolyte LbL assemblies by controlling $\mathrm{pH}$ of $\mathrm{GO}$ suspension to fabricate transparent and super gas barrier films. Nanoscale. 2013a;5(19):9081-8. https://doi.org/10.1039/c3nr02845c.

Chen Y, Qi Y, Liu B. Polyacrylic acid functionalized nanographene as a nanocarrier for loading and controlled release of doxorubicin hydrochloride. J Nanomater. 2013b;2013(5):3805-16. https://doi.org/10.1155/2013/345738 
Chen GY, Chen CL, Tuan HY, Yuan PX, Li KC, Yang HJ, Hu YC. Graphene oxide triggers toll-like receptors/autophagy responses in vitro and inhibits tumor growth in vivo. Adv Healthc Mater. 2014a;3(9):1486-95. https://doi.org/10. 1002/adhm.201300591.

Chen H, Wang Z, Zong S, Wu L, Chen P, Zhu D, Wang C, Xu S, Cui Y. SERS-fluorescence monitored drug release of a redoxresponsive nanocarrier based on graphene oxide in tumor cells. ACS Appl Mater Interfaces. 2014b;6(20):17526-33. https://doi.org/10.1021/am505160v.

Chen J, Wang X, Chen T. Facile and green reduction of covalently PEGylated nanographene oxide via a 'water-only' route for high-efficiency photothermal therapy. Nanoscale Res Lett. 2014c;9(1):86. https://doi.org/10.1186/ 1556-276X-9-86

Chen J, Liu C, Zeng G, You Y, Wang H, Gong X, Zheng R, Kim J, Kim C, Song L. Indocyanine green loaded reduced graphene oxide for in vivo photoacoustic/fluorescence dual-modality tumor imaging. Nanoscale Res Lett. 2016;11(1):85. https://doi.org/10.1186/s11671-016-1288-x.

Chen L, Wang Y, Song J, Deng W, Lu J, Ma L, Yang C, Li M, Xue Y. Phosphoproteome-based kinase activity profiling reveals the critical role of MAP2K2 and PLK1 in neuronal autophagy. Autophagy. 2017a;13(11):1969-80. https://doi.org/10 1080/15548627.2017.1371393.

Chen Y, Zhang F, Wang Q, Tong R, Lin H, Qu F. Near-infrared light-mediated LA-UCNPs@SiO $-\mathrm{C} / \mathrm{HA} @ m \mathrm{mSiO}_{2}-\mathrm{DOX} @ \mathrm{NB}$ nanocomposite for chemotherapy/PDT/PTT and imaging. Dalton Trans. 2017b;46(41):14293-300. https://doi.org/ 10.1039/c7dt02529g.

Chowdhury SM, Surhland C, Sanchez Z, Chaudhary P, Suresh Kumar MA, Lee S, Peña LA, Waring M, Sitharaman B, Naidu M. Graphene nanoribbons as a drug delivery agent for lucanthone mediated therapy of glioblastoma multiforme. Nanomed Nanotechnol Biol Med. 2015;11(1):109-18. https://doi.org/10.1016/j.nano.2014.08.001.

Chua CK, Pumera M. Covalent chemistry on graphene. Chem Soc Rev. 2013:42(8):3222-33. https://doi.org/10.1039/c2cs3 $5474 h$.

Chung C, Kim YK, Shin D, Ryoo SR, Min DH. Biomedical applications of graphene and graphene oxide. Acc Chem Res. 2013;46(10):2211-24. https://doi.org/10.1021/ar300159f.

Cong HP, He JJ, Lu Y, Yu SH. Water-soluble magnetic-functionalized reduced graphene oxide sheets: in situ synthesis and magnetic resonance imaging applications. Small. 2010;6(2):169-73. https://doi.org/10.1002/smll.200901360.

Denkova AG, de Kruijff RM, Serra-Crespo P. Nanocarrier-mediated photochemotherapy and photoradiotherapy. Adv Healthc Mater. 2018;7(8): e1701211. https://doi.org/10.1002/adhm.201701211.

Desbrières J, Martinez C, Rinaudo M. Hydrophobic derivatives of chitosan: characterization and rheological behaviour. Int J Biol Macromol. 1996;19(1):21-8. https://doi.org/10.1016/0141-8130(96)01095-1.

Di Santo R, Quagliarini E, Palchetti S, Pozzi D, Palmieri V, Perini G. Microfluidic-generated lipid-graphene oxide nanoparticles for gene delivery. Appl Phys Lett. 2019;114(23):233701.1-233701.5. https://doi.org/10.1063/1.5100932.

Díez-Pascual AM, Díez-Vicente AL. Poly(propylene fumarate)/polyethylene glycol-modified graphene oxide nanocomposites for tissue engineering. ACS Appl Mater Interfaces. 2016;8(28):17902-14. https://doi.org/10.1021/acsami. $6 b 05635$.

Dinescu S, lonita M, Ignat SR, Costache M, Hermenean A. Graphene oxide enhances chitosan-based 3D scaffold properties for bone tissue engineering. Int J Mol Sci. 2019;20(20):5077. https://doi.org/10.3390/ijms20205077.

Ding Y, Zhou L, Chen X, Wu Q, Song Z, Wei S, Zhou J, Shen J. Mutual sensitization mechanism and self-degradation property of drug delivery system for in vitro photodynamic therapy. Int J Pharm. 2016;498(1-2):335-46. https://doi.org/ 10.1016/j.jpharm.2015.12.044.

Dong H, Zhao Z, Wen H, Guo F, Shen A, Pilger F, Lin C, Shi D. Poly (ethylene glycol) conjugated nano-graphene oxide for photodynamic therapy. Sci China Chem. 2010;53(011):2265-71. https://doi.org/10.1007/s11426-010-4114-9.

Dou R, Du Z, Bao T, Dong X, Zheng X, Yu M, Yin W, Dong B, Yan L, Gu Z. The polyvinylpyrrolidone functionalized rGO/ $\mathrm{Bi}_{2} \mathrm{~S}_{3}$ nanocomposite as a near-infrared light-responsive nanovehicle for chemo-photothermal therapy of cancer. Nanoscale. 2016;8(22):11531-42. https://doi.org/10.1039/c6nr01543c.

Dreaden EC, Mackey MA, Huang X, Kang B, El-Sayed MA. Beating cancer in multiple ways using nanogold. Chem Soc Rev. 2011;40(7):3391-404. https://doi.org/10.1039/c0cs00180e.

Du L, Wu S, Li Y, Zhao X, Ju X, Wang Y. Cytotoxicity of PEGylated graphene oxide on lymphoma cells. Bio-Med Mater Eng. 2014;24(6):2135-41. https://doi.org/10.3233/BME-141024

Du B, Liu J, Ding G, Han X, Li D, Wang E. Positively charged graphene/ $/ \mathrm{Fe}_{3} \mathrm{O}_{4} /$ polyethylenimine with enhanced drug loading and cellular uptake for magnetic resonance imaging and magnet-responsive cancer therapy. Nano Res. 2017;10(007):2280-95. https://doi.org/10.1007/S12274-016-1418-X.

Du S, Wang Y, Ao J, Wang K, Zhang Z, Yang L. Targeted delivery of sirna to ovarian cancer cells using functionalized graphene oxide. Nano Life. 2018. https://doi.org/10.1142/S1793984418500010.

Durán N, Martinez DS, Silveira CP, Durán M, de Moraes AC, Simões MB, Alves OL, Fávaro WJ. Graphene oxide: a carrier for pharmaceuticals and a scaffold for cell interactions. Curr Top Med Chem. 2015;15(4):309-27. https://doi.org/10. 2174/1568026615666150108144217.

Durán M, Durán N, Fávaro WJ. In vivo nanotoxicological profile of graphene oxide. J Phys Conf Ser. 2017;838(1):012026. https://doi.org/10.1088/1742-6596/838/1/012026.

Ege D, Kamali A, Boccaccini A. Graphene oxide/polymer-based biomaterials. Adv Eng Mater. 2017;19:1700627. https://doi. org/10.1002/adem.201700627.

Fan L, Ge H, Zou S, Xiao Y, Wen H, Li Y, Feng H, Nie M. Sodium alginate conjugated graphene oxide as a new carrier for drug delivery system. Int J Biol Macromol. 2016;93(Pt A):582-90. https://doi.org/10.1016/j.jibiomac.2016.09.026.

Feng L, Yang X, Shi X, Tan X, Peng R, Wang J, Liu Z. Polyethylene glycol and polyethylenimine dual-functionalized nanographene oxide for photothermally enhanced gene delivery. Small. 2013;9(11):1989-97. https://doi.org/10.1002/ smll.201202538.

Gao L, Yu J, Liu Y, Zhou J, Sun L, Wang J, Zhu J, Peng H, Lu W, Yu L, Yan Z, Wang Y. Tumor-penetrating peptide conjugated and doxorubicin loaded $\mathrm{T}_{1}-\mathrm{T}_{2}$ dual mode MRI contrast agents nanoparticles for tumor theranostics. Theranostics. 2018;8(1):92-108. https://doi.org/10.7150/thno.21074. 
Gao Y, Ma Q, Cao J, Wang Y, Yang X, Xu Q, Liang Q, Sun Y. Recent advances in microfluidic-aided chitosan-based multifunctional materials for biomedical applications. Int J Pharm. 2021;600: 120465. https://doi.org/10.1016/j.jpharm. 2021.120465.

Georgakilas V, Otyepka M, Bourlinos AB, Chandra V, Kim N, Kemp KC, Hobza P, Zboril R, Kim KS. Functionalization of graphene: covalent and non-covalent approaches, derivatives and applications. Chem Rev. 2012;112(11):6156-214. https://doi.org/10.1021/cr3000412.

Ghosh S, Chatterjee K. Poly (ethylene glycol) functionalized graphene oxide in tissue engineering: a review on recent advances. Int J Nanomed. 2020;15:5991-6006. https://doi.org/10.2147/IJN.S249717.

Gollavelli G, Ling YC. Multi-functional graphene as an in vitro and in vivo imaging probe. Biomaterials. 2012;33(8):253245. https://doi.org/10.1016/j.biomaterials.2011.12.010.

Gong P, Ji S, Wang J, Dai D, Wang F, Tian M. Fluorescence-switchable ultrasmall fluorinated graphene oxide with high near-infrared absorption for controlled and targeted drug delivery. Chem Eng J. 2018;348:438-46. https://doi.org/ 10.1016/j.cej.2018.04.193.

Guo X, Huang L. Recent advances in nonviral vectors for gene delivery. Acc Chem Res. 2012;45(7):971-9. https://doi.org/ 10.1021 /ar200151m.

Guo X, Mei N. Assessment of the toxic potential of graphene family nanomaterials. J Food Drug Anal. 2014;22(1):105-15. https://doi.org/10.1016/j.jfda.2014.01.009.

Guo M, Mao H, Li Y, Zhu A, He H, Yang H, Wang Y, Tian X, Ge C, Peng Q, Wang X, Yang X, Chen X, Liu G, Chen H. Dual imaging-guided photothermal/photodynamic therapy using micelles. Biomaterials. 2014;35(16):4656-66. https:// doi.org/10.1016/j.biomaterials.2014.02.018.

Gurunathan S, Han JW, Eppakayala V, Kim JH. Green synthesis of graphene and its cytotoxic effects in human breast cancer cells. Int J Nanomed. 2013:8:1015-27. https://doi.org/10.2147/IJN.S42047.

Gurunathan S, Han JW, Kim ES, Park JH, Kim JH. Reduction of graphene oxide by resveratrol: a novel and simple biological method for the synthesis of an effective anticancer nanotherapeutic molecule. Int J Nanomed. 2015;10:2951-69. https://doi.org/10.2147/IJN.S79879.

Han H, Wang H, Chen Y, Li Z, Wang Y, Jin Q, Ji J. Theranostic reduction-sensitive gemcitabine prodrug micelles for nearinfrared imaging and pancreatic cancer therapy. Nanoscale. 2016;8(1):283-91. https://doi.org/10.1039/c5nr0 $6734 \mathrm{k}$.

He S, Song J, Qu J, Cheng Z. Crucial breakthrough of second near-infrared biological window fluorophores: design and synthesis toward multimodal imaging and theranostics. Chem Soc Rev. 2018;47(12):4258-78. https://doi.org/10. 1039/c8cs00234g.

Hoseini-Ghahfarokhi M, Mirkiani S, Mozaffari N, Abdolahi Sadatlu MA, Ghasemi A, Abbaspour S, Akbarian M, Farjadain F, Karimi M. Applications of graphene and graphene oxide in smart drug/gene delivery: is the world still flat? Int J Nanomed. 2020;15:9469-96. https://doi.org/10.2147/JNN.S265876.

Hosseinzadeh R, Khorsandi K, Hosseinzadeh G. Graphene oxide-methylene blue nanocomposite in photodynamic therapy of human breast cancer. J Biomol Struct Dyn. 2018;36(9):2216-23. https://doi.org/10.1080/07391102.2017 1345698.

Hu D, Zhang J, Gao G, Sheng Z, Cui H, Cai L. Indocyanine green-loaded polydopamine-reduced graphene oxide nanocomposites with amplifying photoacoustic and photothermal effects for cancer theranostics. Theranostics. 2016;6(7):1043-52. https://doi.org/10.7150/thno.14566.

Huang P, Lin J, Wang S, Zhou Z, Li Z, Wang Z, Zhang C, Yue X, Niu G, Yang M, Cui D, Chen X. Photosensitizer-conjugated silica-coated gold nanoclusters for fluorescence imaging-guided photodynamic therapy. Biomaterials. 2013;34(19):4643-54. https://doi.org/10.1016/j.biomaterials.2013.02.063.

Huang P, Rong P, Lin J, Li W, Yan X, Zhang MG, Nie L, Niu G, Lu J, Wang W, Chen X. Triphase interface synthesis of plasmonic gold bellflowers as near-infrared light mediated acoustic and thermal theranostics. J Am Chem Soc. 2014;136(23):8307-13. https://doi.org/10.1021/ja503115n.

Huang P, Wang S, Wang X, Shen G, Lin J, Wang Z, Guo S, Cui D, Yang M, Chen X. Surface functionalization of chemically reduced graphene oxide for targeted photodynamic therapy. J Biomed Nanotechnol. 2015;11(1):117-25. https:// doi.org/10.1166/jbn.2015.2055.

Hummers WSH Jr, Offeman RE. Preparation of graphitic oxide. J Am Chem Soc. 1958. https://doi.org/10.1021/ja015 39a017?journalCode=jacsat.

Jiang W, Mo F, Lin Y, Wang X, Xu L, Fu F. Tumor targeting dual stimuli responsive controllable release nanoplatform based on DNA-conjugated reduced graphene oxide for chemo-photothermal synergetic cancer therapy. J Mater Chem B. 2018;6(26):4360-7. https://doi.org/10.1039/c8tb00670a.

Jichlinski P, Leisinger HJ. Photodynamic therapy in superficial bladder cancer: past, present and future. Urol Res. 2001;29(6):396-405. https://doi.org/10.1007/s002400100215.

Kakran M, Sahoo NG, Bao H, Pan Y, Li L. Functionalized graphene oxide as nanocarrier for loading and delivery of ellagic acid. Curr Med Chem. 2011;18(29):4503-12. https://doi.org/10.2174/092986711797287548.

Kalluru P, Vankayala R, Chiang CS, Hwang KC. Nano-graphene oxide-mediated in vivo fluorescence imaging and bimodal photodynamic and photothermal destruction of tumors. Biomaterials. 2016;95:1-10. https://doi.org/10.1016/j. biomaterials.2016.04.006.

Karlický F, Kumara Ramanatha Datta K, Otyepka M, Zboriil R. Halogenated graphenes: rapidly growing family of graphene derivatives. ACS Nano. 2013;7(8):6434-64. https://doi.org/10.1021/nn4024027.

Khdair A, Handa H, Mao G, Panyam J. Nanoparticle-mediated combination chemotherapy and photodynamic therapy overcomes tumor drug resistance in vitro. Eur J Pharm Biopharm. 2009;71(2):214-22. https://doi.org/10.1016/j. ejpb.2008.08.017.

Kiew SF, Kiew LV, Lee HB, Imae T, Chung LY. Assessing biocompatibility of graphene oxide-based nanocarriers: a review. J Control Release. 2016;226:217-28. https://doi.org/10.1016/j.jconrel.2016.02.015.

Kim H, Kim WJ. Photothermally controlled gene delivery by reduced graphene oxide-polyethylenimine nanocomposite. Small. 2014;10(1):117-26. https://doi.org/10.1002/smll.201202636. 
Kim H, Namgung R, Singha K, Oh IK, Kim WJ. Graphene oxide-polyethylenimine nanoconstruct as a gene delivery vector and bioimaging tool. Bioconjug Chem. 2011a;22(12):2558-67. https://doi.org/10.1021/bc200397j.

Kim YK, Kim MH, Min DH. Biocompatible reduced graphene oxide prepared by using dextran as a multifunctional reducing agent. Chem Commun. 2011b;47(11):3195-231. https://doi.org/10.1039/c0cc05005a.

Komisar DA, Krivova GM, Stebunov YV, Yakubovsky DI, Volkov VS. Optical properties of thin graphene oxide films and their biosensing applications. J Phys: Conf Ser. 2020;1461: 012068. https://doi.org/10.1088/1742-6596/1461/1/012068.

Lalwani G, Cai X, Nie L, Wang LV, Sitharaman B. Graphene-based contrast agents for photoacoustic and thermoacoustic tomography. Photoacoustics. 2013;1(3-4):62-7. https://doi.org/10.1016/j.pacs.2013.10.001.

Lee N, Choi SH, Hyeon T. Nano-sized CT contrast agents. Adv Mater. 2013;25(19):2641-60. https://doi.org/10.1002/adma. 201300081

Lee JY, Termsarasab U, Park JH, Lee SY, Ko SH, Shim JS, Chung SJ, Cho HJ, Kim DD. Dual CD44 and folate receptor-targeted nanoparticles for cancer diagnosis and anticancer drug delivery. J Control Release. 2016;236:38-46. https://doi. org/10.1016/j.jconrel.2016.06.021.

Li Y, Lu W, Huang Q, Huang M, Li C, Chen W. Copper sulfide nanoparticles for photothermal ablation of tumor cells. Nanomedicine. 2010:5(8):1161-71. https://doi.org/10.2217/nnm.10.85.

Li M, Yang X, Ren J, Qu K, Qu X. Using graphene oxide high near-infrared absorbance for photothermal treatment of Alzheimer's disease. Adv Mater. 2012a;24(13):1722-8. https://doi.org/10.1002/adma.201104864.

Li Y, Liu Y, Fu Y, Wei T, Le Guyader L, Gao G, Liu RS, Chang YZ, Chen C. The triggering of apoptosis in macrophages by pristine graphene through the MAPK and TGF-beta signaling pathways. Biomaterials. 2012b;33(2):402-11. https:// doi.org/10.1016/j.biomaterials.2011.09.091.

Li JL, Tang B, Yuan B, Sun L, Wang XG. A review of optical imaging and therapy using nanosized graphene and graphene oxide. Biomaterials. 2013;34(37):9519-34. https://doi.org/10.1016/j.biomaterials.2013.08.066.

Li Y, Feng L, Shi X, Wang X, Yang Y, Yang K, Liu T, Yang G, Liu Z. Surface coating-dependent cytotoxicity and degradation of graphene derivatives: towards the design of non-toxic, degradable nano-graphene. Small. 2014;10(8):1544-54. https://doi.org/10.1002/smll.201303234.

Li Y, Dong H, Li Y, Shi D. Graphene-based nanovehicles for photodynamic medical therapy. Int J Nanomed. 2015;10:24519. https://doi.org/10.2147/IJN.S68600.

Li T, Liu H, Xi G, Pang Y, Wu L, Wang X, Chen T. One-step reduction and PElylation of PEGylated nanographene oxide for highly efficient chemo-photothermal therapy. J Mater Chem B. 2016:4(17):2972-83. https://doi.org/10.1039/c6tb0 0486e.

Li Q, Hong L, Li H, Liu C. Graphene oxide-fullerene $\mathrm{C}_{60}\left(\mathrm{GO}-\mathrm{C}_{60}\right)$ hybrid for photodynamic and photothermal therapy triggered by near-infrared light. Biosens Bioelectron. 2017;89(Pt 1):477-82. https://doi.org/10.1016/j.bios.2016.03.072.

Li X, Lovell JF, Yoon J, Chen X. Clinical development and potential of photothermal and photodynamic therapies for cancer. Nat Rev Clin Oncol. 2020;17(11):657-74. https://doi.org/10.1038/s41571-020-0410-2.

Lim JH, Kim DE, Kim EJ, Ahrberg CD, Chung BG. Functional graphene oxide-based nanosheets for photothermal therapy. Macromol Res. 2018;26:557-65. https://doi.org/10.1007/s13233-018-6067-3.

Lin J, Chen X, Huang P. Graphene-based nanomaterials for bioimaging. Adv Drug Deliv Rev. 2016;105:242-54. https://doi. org/10.1016/j.addr.2016.05.013.

Lin W, Zhang X, Qian L, Yao N, Pan Y, Zhang L. Doxorubicin-loaded unimolecular micelle-stabilized gold nanoparticles as a theranostic nanoplatform for tumor-targeted chemotherapy and computed tomography imaging. Biomacromol. 2017;18(12):3869-80. https://doi.org/10.1021/acs.biomac.7b00810.

Lin D, Wu Z, Huang Y, Wu J, Li C, Qin W. Physical, mechanical, structural and antibacterial properties of polyvinyl alcohol/ oregano oil/graphene oxide composite films. J Polym Environ. 2020;28(2):638-46. https://doi.org/10.1007/ s10924-019-01627-4.

Liu Z, Robinson JT, Sun X, Dai H. PEGylated nanographene oxide for delivery of water-insoluble cancer drugs. J Am Chem Soc. 2008;130(33):10876-7. https://doi.org/10.1021/ja803688x.

Liu K, Zhang JJ, Cheng FF, Zheng TT, Zhu JJ. Green and facile synthesis of highly biocompatible graphene nanosheets and its application for cellular imaging and drug delivery. J Mater Chem. 2011;21(32):12034-40. https://doi.org/10. 1039/C1JM10749F.

Liu Z, Guo Z, Zhong H, Qin X, Wan M, Yang B. Graphene oxide based surface-enhanced Raman scattering probes for cancer cell imaging. Phys Chem Chem Phys. 2013a;15(8):2961-6. https://doi.org/10.1039/c2cp43715e.

Liu J, Cui L, Losic D. Graphene and graphene oxide as new nanocarriers for drug delivery applications. Acta Biomater. 2013b;9(12):9243-57. https://doi.org/10.1016/j.actbio.2013.08.016

Liu Y, Luo Y, Wu J, Wang Y, Yang X, Yang R, Wang B, Yang J, Zhang N. Graphene oxide can induce in vitro and in vivo mutagenesis. Sci Rep. 2013c;3:3469. https://doi.org/10.1038/srep03469.

Liu T, Wang C, Cui W, Gong H, Liang C, Shi X, Li Z, Sun B, Liu Z. Combined photothermal and photodynamic therapy delivered by PEGylated MoS, nanosheets. Nanoscale. 2014;6(19):11219-25. https://doi.org/10.1039/c4nr03753g.

Liu G, Qin H, Amano T, Murakami T, Komatsu N. Direct fabrication of the graphene-based composite for cancer phototherapy through graphite exfoliation with a photosensitizer. ACS Appl Mater Interfaces. 2015a;7(42):23402-6. https://doi.org/10.1021/acsami.5b07432.

Liu L, Wei Y, Zhai S, Chen Q, Xing D. Dihydroartemisinin and transferrin dual-dressed nano-graphene oxide for a pHtriggered chemotherapy. Biomaterials. 2015b;62:35-46. https://doi.org/10.1016/j.biomaterials.2015.05.036.

Liu Y, Fang N, Liu B, Song L, Wen B, Yang D. Aligned porous chitosan/graphene oxide scaffold for bone tissue engineering. Mater Lett. 2018;233(15):78-81. https://doi.org/10.1016/j.matlet.2018.08.108.

Liu Y, Bhattarai P, Dai Z, Chen X. Photothermal therapy and photoacoustic imaging via nanotheranostics in fighting cancer. Chem Soc Rev. 2019:48(7):2053-108. https://doi.org/10.1039/c8cs00618k.

Loutfy SA, Salaheldin TA, Ramadan MA, Farroh K, Abdallah ZF, Youssef T. Synthesis, characterization and cytotoxic evaluation of graphene oxide nanosheets: in vitro liver cancer model. Asian Pac J Cancer Prev. 2017;18(4):955-61. https:// doi.org/10.22034/APJCP.2017.18.4.955.

Lu CH, Yang HH, Zhu CL, Chen X, Chen GN. A graphene platform for sensing biomolecules. Angew Chem. 2009;48(26):4785-7. https://doi.org/10.1002/anie.200901479 (International ed. in English). 
Lu N, Wang L, Lv M, Tang Z, Fan C. Graphene-based nanomaterials in biosystems. Nano Res. 2019;12(2):247-64. https:// doi.org/10.1007/s12274-018-2209-3.

Lv Y, Tao L, Annie Bligh SW, Yang H, Pan Q, Zhu L. Targeted delivery and controlled release of doxorubicin into cancer cells using a multifunctional graphene oxide. Mater Sci Eng C Mater Biol Appl. 2016;59:652-60. https://doi.org/10. 1016/j.msec.2015.10.065.

Ma J, Zhang J, Xiong Z, Yong Y, Zhao XS. Preparation, characterization and antibacterial properties of silver-modified graphene oxide. J Mater Chem. 2011;21(10):3350-2. https://doi.org/10.1039/c0jm02806a.

Ma J, Liu R, Wang X, Liu Q, Chen Y, Valle RP, Zuo YY, Xia T, Liu S. Crucial role of lateral size for graphene oxide in activating macrophages and stimulating pro-inflammatory responses in cells and animals. ACS Nano. 2015;9(10):10498-515. https://doi.org/10.1021/acsnano.5b04751.

Ma N, Liu J, He W, Li Z, Luan Y, Song Y, Garg S. Folic acid-grafted bovine serum albumin decorated graphene oxide: an efficient drug carrier for targeted cancer therapy. J Colloid Interface Sci. 2017;490:598-607. https://doi.org/10. 1016/j.jcis.2016.11.097.

Ma Q, Gao Y, Sun W, Cao J, Liang Y, Han S, Wang X, Sun Y. Self-assembled chitosan/phospholipid nanoparticles: from fundamentals to preparation for advanced drug delivery. Drug Deliv. 2020a;27(1):200-15. https://doi.org/10.1080/ 10717544.2020 .1716878

Ma Q, Cao J, Gao Y, Han S, Liang Y, Zhang T, Wang X, Sun Y. Microfluidic-mediated nano-drug delivery systems: from fundamentals to fabrication for advanced therapeutic applications. Nanoscale. 2020b;12:15512-27. https://doi. org/10.1039/d0nr02397c.

Ma Q, Song Y, Sun W, Cao J, Yuan H, Wang X, Sun Y, Shum HC. Cell-inspired all-aqueous microfluidics: from intracellular liquid-liquid phase separation toward advanced biomaterials. Adv Sci. 2020c;7(7):31. https://doi.org/10.1002/advs. 201903359.

Ma Q, Haixia Ma H, Xu F, Wang X, Sun W. Microfluidics in cardiovascular disease research: state of the art and future outlook. Microsyst Nanoeng. 2021;7(1):19. https://doi.org/10.1038/s41378-021-00245-2.

Marcano DC, Kosynkin DV, Berlin JM, Sinitskii A, Sun Z, Slesarev A, Alemany LB, Lu W, Tour JM. Improved synthesis of graphene oxide. ACS Nano. 2010;4(8):4806-14. https://doi.org/10.1021/nn1006368.

Mattheolabakis G, Milane L, Singh A, Amiji MM. Hyaluronic acid targeting of CD44 for cancer therapy: from receptor biology to nanomedicine. J Drug Target. 2015;23(7-8):605-18. https://doi.org/10.3109/1061186X.2015.1052072.

Meng J, Chen X, Tian Y, Li Z, Zheng Q. Nanoscale metal-organic frameworks decorated with graphene oxide for magnetic resonance imaging guided photothermal therapy. Chemistry. 2017;23(69):17521-30. https://doi.org/10. 1002/chem.201702573.

Menon JU, Jadeja P, Tambe P, Vu K, Yuan B, Nguyen KT. Nanomaterials for photo-based diagnostic and therapeutic applications. Theranostics. 2013:3(3):152-66. https://doi.org/10.7150/thno.5327.

Miyanda PM, Gautam S. Graphene oxide: a potential drug carrier for cancer therapy—review. Res Rev J Pharm Sci. 2017;8(3):21-31.

Moon H, Kumar D, Kim H, Sim C, Chang JH, Kim JM, Kim H, Lim DK. Amplified photoacoustic performance and enhanced photothermal stability of reduced graphene oxide coated gold nanorods for sensitive photoacoustic imaging. ACS Nano. 2015;9(3):2711-9. https://doi.org/10.1021/nn506516p.

Mousavi SM, Low FW, Hashemi SA, Samsudin NA, Goh SM. Development of hydrophobic reduced graphene oxide as new approach efficient photochemotherapy. RSC Adv. 2020;10(22):12851-63. https://doi.org/10.1039/d0ra0 0186d.

Mu L, Gao Y, Hu X. L-Cysteine: a biocompatible, breathable and beneficial coating for graphene oxide. Biomaterials. 2015;52:301-11. https://doi.org/10.1016/j.biomaterials.2015.02.046.

Muoz R, Singh DP, Kumar R, Matsuda A. Graphene oxide for drug delivery and cancer therapy. In: Nanostructured polymer composites for biomedical applications. Cambridge: Elsevier; 2019. p. 447-88. https://doi.org/10.1016/ B978-0-12-816771-7.00023-5.

Muroya T, Suehiro Y, Umayahara K, Akiya T, Iwabuchi H, Sakunaga H, Sakamoto M, Sugishita T, Tenjin Y. Gan to kagaku ryoho. Cancer Chemother. 1996;23(1):47-56.

Nascimento TL, Hillaireau H, Vergnaud J, Fattal E. Lipid-based nanosystems for CD44 targeting in cancer treatment: recent significant advances, ongoing challenges and unmet needs. Nanomedicine. 2016;11(14):1865-87. https://doi.org/ 10.2217/nnm-2016-5000.

Ocsoy I, Isiklan N, Cansiz S, Özdemir N, Tan W. ICG-conjugated magnetic graphene oxide for dual photothermal and photodynamic therapy. RSC Adv. 2016;6(36):30285-92. https://doi.org/10.1039/C6RA0679.

Olad A, Hagh K. Graphene oxide and amin-modified graphene oxide incorporated chitosan-gelatin scaffolds as promising materials for tissue engineering. Compos B Eng. 2019;162(1):692-702. https://doi.org/10.1016/j.compositesb. 2019.01.040.

Orecchioni M, Ménard-Moyon C, Delogu LG, Bianco A. Graphene and the immune system: challenges and potentiality. Adv Drug Deliv Rev. 2016;105:163-75. https://doi.org/10.1016/j.addr.2016.05.014.

Pang J, Kang Z, Wang R, Xu B, Nie X, Fan L, Zhang F, Du X, Feng S, Sun D. Exploring the sandwich antibacterial membranes based on uio-66/graphene oxide for forward osmosis performance. Carbon. 2019;144:321-32. https://doi.org/10. 1016/j.carbon.2018.12.050

Peer D, Karp JM, Hong S, Farokhzad OC, Margalit R, Langer R. Nanocarriers as an emerging platform for cancer therapy. Nat Nanotechnol. 2007;2(12):751-60. https://doi.org/10.1038/nnano.2007.387.

Peng E, Choo ES, Chandrasekharan P, Yang CT, Ding J, Chuang KH, Xue JM. Synthesis of manganese ferrite/graphene oxide nanocomposites for biomedical applications. Small. 2012;8(23):3620-30. https://doi.org/10.1002/smll.20120 1427.

Poinard B, Neo S, Yeo E, Heng H, Neoh KG, Kah J. Polydopamine nanoparticles enhance drug release for combined photodynamic and photothermal therapy. ACS Appl Mater Interfaces. 2018;10(25):21125-36. https://doi.org/10. 1021/acsami.8b04799.

Qian X, Gu Z, Chen Y. Two-dimensional black phosphorus nanosheets for theranostic nanomedicine. Mater Horiz. 2017;4:800-16. https://doi.org/10.1039/C7MH00305F. 
Qiao Z, Zhang H, Wang K, Zhang Y. A highly sensitive and responsive fluorescent probe based on 6-azidechroman dye for detection and imaging of hydrogen sulfide in cells. Talanta. 2019;195:850-6. https://doi.org/10.1016/j.talanta.2018. 12.014.

Qu G, Liu S, Zhang S, Wang L, Wang X, Sun B, Yin N, Gao X, Xia T, Chen JJ, Jiang GB. Graphene oxide induces toll-like receptor 4 (TLR4)-dependent necrosis in macrophages. ACS Nano. 2013;7(7):5732-45. https://doi.org/10.1021/ nn402330b.

Qu Y, He F, Yu C, Liang X, Liang D, Ma L, Zhang Q, Lv J, Wu J. Advances on graphene-based nanomaterials for biomedical applications. Mater Sci Eng C Mater Biol Appl. 2018;90:764-80. https://doi.org/10.1016/j.msec.2018.05.018.

Ramalingam M, Wang X, Chen G, Ma P, Cui FZ. The emerging applications of graphene oxide and graphene in tissue engineering. Wiley; 2013.

Rao Z, Ge H, Liu L, Zhu C, Min L, Liu M, Fan L, Li D. Carboxymethyl cellulose modified graphene oxide as pH-sensitive drug delivery system. Int J Biol Macromol. 2018;107:1184-92. https://doi.org/10.1016/j.jibiomac.2017.09.096.

Rosenthal A, Mantz A, Nguyen A, Bittrich E, Schubert E, Schubert M, Stamm M, Pannier AK, Uhlmann P. Biofunctionalization of titanium substrates using nanoscale polymer brushes with cell adhesion peptides. J Phys Chem B. 2018;122(25):6543-50. https://doi.org/10.1021/acs.jpcb.8b02407.

Sahu A, Choi WI, Lee JH, Tae G. Graphene oxide mediated delivery of methylene blue for combined photodynamic and photothermal therapy. Biomaterials. 2013;34(26):6239-48. https://doi.org/10.1016/j.biomaterials.2013.04.066.

Shang $\mathrm{H}$, Han D, Ma M, Li S, Xue W, Zhang A. Enhancement of the photokilling effect of $\mathrm{TiO}_{2}$ in photodynamic therapy by conjugating with reduced graphene oxide and its mechanism exploration. J Photochem Photobiol B Biol. 2017;177:112-23. https://doi.org/10.1016/j.jphotobiol.2017.10.016

Sharma H, Mondal S. Functionalized graphene oxide for chemotherapeutic drug delivery and cancer treatment: a promising material in nanomedicine. Int J Mol Sci. 2020:21(17):6280. https://doi.org/10.3390/ijms21176280.

Sharman WM, Allen CM, van Lier JE. Photodynamic therapeutics: basic principles and clinical applications. Drug Discov Today. 1999;4(11):507-17. https://doi.org/10.1016/s1359-6446(99)01412-9.

Shen H, Zhang L, Liu M, Zhang Z. Biomedical applications of graphene. Theranostics. 2012;2(3):283-94. https://doi.org/10. 7150/thno.3642.

Shen Z, Ma Q, Zhou X, Zhang G, Hao G, Sun Y, Cao J. Strategies to improve photodynamic therapy efficacy by relieving the tumor hypoxia environment. NPG Asia Mater. 2021;13:39. https://doi.org/10.1038/s41427-021-00303-1.

Sheng Z, Song L, Zheng J, Hu D, He M, Zheng M, Gao G, Gong P, Zhang P, Ma Y, Cai L. Protein-assisted fabrication of nanoreduced graphene oxide for combined in vivo photoacoustic imaging and photothermal therapy. Biomaterials. 2013;34(21):5236-43. https://doi.org/10.1016/j.biomaterials.2013.03.090.

Shi S, Yang K, Hong H, Valdovinos HF, Nayak TR, Zhang Y, Theuer CP, Barnhart TE, Liu Z, Cai W. Tumor vasculature targeting and imaging in living mice with reduced graphene oxide. Biomaterials. 2013;34(12):3002-9. https://doi.org/10. 1016/j.biomaterials.2013.01.047.

Shi J, Wang L, Zhang J, Ma R, Gao J, Liu Y, Zhang C, Zhang Z. A tumor-targeting near-infrared laser-triggered drug delivery system based on GO@Ag nanoparticles for chemo-photothermal therapy and X-ray imaging. Biomaterials. 2014;35(22):5847-61. https://doi.org/10.1016/..biomaterials.2014.03.042.

Shin YC, Kim J, Kim SE, Song SJ, Hong SW, Oh JW, Lee J, Park JC, Hyon SH, Han DW. RGD peptide and graphene oxide co-functionalized PLGA nanofiber scaffolds for vascular tissue engineering. Regener Biomater. 2017;4(3):159-66. https://doi.org/10.1093/rb/rbx001.

Singh DP, Herrera CE, Singh B, Singh S, Singh RK, Kumar R. Graphene oxide: an efficient material and recent approach for biotechnological and biomedical applications. Mater Sci Eng C Mater Biol Appl. 2018;86:173-97. https://doi.org/ 10.1016/j.msec.2018.01.004.

Song E, Han W, Li C, Cheng D, Li L, Liu L, Zhu G, Song Y, Tan W. Hyaluronic acid-decorated graphene oxide nanohybrids as nanocarriers for targeted and pH-responsive anticancer drug delivery. ACS Appl Mater Interfaces. 2014;6(15):11882-90. https://doi.org/10.1021/am502423r.

Song J, Wang F, Yang X, Ning B, Harp MG, Culp SH, Hu S, Huang P, Nie L, Chen J, Chen X. Gold nanoparticle coated carbon nanotube ring with enhanced Raman scattering and photothermal conversion property for theranostic applications. J Am Chem Soc. 2016;138(22):7005-15. https://doi.org/10.1021/jacs.5b13475.

Song C, Dou Y, Yuwen L, Sun Y, Dong C, Li F, Yang Y, Wang L. A gold nanoflower-based traceable drug delivery system for intracellular SERS imaging-guided targeted chemo-phototherapy. J Mater Chem B. 2018a;6(19):3030-9. https:// doi.org/10.1039/c8tb00587g.

Song S, Chong Y, Fu H, Ning X, Shen H, Zhang Z. HP- $\beta$-CD functionalized $\mathrm{Fe}_{3} \mathrm{O}_{4} / \mathrm{CNPs}$-based theranostic nanoplatform for $\mathrm{pH} / \mathrm{NIR}$ responsive drug release and $\mathrm{mr} /$ nirfl imaging-guided synergetic chemo/photothermal therapy of tumor. ACS Appl Mater Interfaces. 2018b;10(40):33867-78. https://doi.org/10.1021/acsami.8b09999.

Song S, Shen H, Wang Y, Chu X, Xie J, Zhou N, Shen J. Biomedical application of graphene: from drug delivery, tumor therapy, to theranostics. Colloids Surf B Biointerfaces. 2020;185:1 10596. https://doi.org/10.1016/j.colsurfb.2019.110596.

Sun X, Liu Z, Welsher K, Robinson JT, Goodwin A, Zaric S, Dai H. Nano-graphene oxide for cellular imaging and drug delivery. Nano Res. 2008;1(3):203-12. https://doi.org/10.1007/s12274-008-8021-8.

Tang X, Yu H, Bui B, Wang L, Xing C, Wang S, Chen M, Hu Z, Chen W. Nitrogen-doped fluorescence carbon dots as multimechanism detection for iodide and curcumin in biological and food samples. Bioact Mater. 2020;6(6):1541-54. https://doi.org/10.1016/j.bioactmat.2020.11.006.

Tao Y, Ju E, Liu Z, Dong K, Ren J, Qu X. Engineered, self-assembled near-infrared photothermal agents for combined tumor immunotherapy and chemo-photothermal therapy. Biomaterials. 2014;35(24):6646-56. https://doi.org/10. 1016/j.biomaterials.2014.04.073.

Thirunavukkarasu GK, Cherukula K, Lee H, Jeong YY, Park IK, Lee JY. Magnetic field-inducible drug-eluting nanoparticles for image-guided thermo-chemotherapy. Biomaterials. 2018;180:240-52. https://doi.org/10.1016/j.biomaterials. 2018.07.028.

Tikhonov VE, Stepnova EA, Babak VG, Yamskov IA, Palma-Guerrero J, Jansson HB. Bactericidal and antifungal activities of a low molecular weight chitosan and its n-/2(3)-(dodec-2-enyl)succinoyl/-derivatives. Carbohydr Polym. 2006;64(1):66-72. https://doi.org/10.1016/j.carbpol.2005.10.021. 
Ting S, Furong C, Jianqin Y, Jun C, Kui L, Yuji P. Hierarchical nanocomposites of graphene oxide and pegylated protoporphyrin as carriers to load doxorubicin hydrochloride for trimodal synergistic therapy. J Mater Chem B. 2018;6(28):4687-96. https://doi.org/10.1039/c8tb00733k.

Tran AV, Shim K, Thi TT, Kook JK, An SS, Lee SW. Targeted and controlled drug delivery by multifunctional mesoporous silica nanoparticles with internal fluorescent conjugates and external polydopamine and graphene oxide layerssciencedirect. Acta Biomater. 2018;74:397-413. https://doi.org/10.1016/j.actbio.2018.05.022.

Trindade GS, Farias SL, Rumjanek VM, Capella MA. Methylene blue reverts multidrug resistance: sensitivity of multidrug resistant cells to this dye and its photodynamic action. Cancer Lett. 2000;151(2):161-7. https://doi.org/10.1016/ s0304-3835(99)00408-5.

Vila M, Matesanz MC, Gonçalves G, Feito MJ, Linares J, Marques PA, Portolés MT, Vallet-Regi M. Triggering cell death by nanographene oxide mediated hyperthermia. Nanotechnology. 2014;25(3): 035101. https://doi.org/10.1088/09574484/25/3/035101.

Wang K, Ruan J, Song H, Zhang J, Wo Y, Guo S, Cui D. Biocompatibility of graphene oxide. Nanoscale Res Lett. 2011;6(1):8. https://doi.org/10.1007/s11671-010-9751-6.

Wang Y, Wang H, Liu D, Song S, Wang X, Zhang H. Graphene oxide covalently grafted upconversion nanoparticles for combined NIR mediated imaging and photothermal/photodynamic cancer therapy. Biomaterials. 2013;34(31):7715-24. https://doi.org/10.1016/j.biomaterials.2013.06.045.

Wang F, Sun Q, Feng B, Xu Z, Zhang J, Xu J, Lu L, Yu H, Wang M, Li Y, Zhang W. Polydopamine-functionalized graphene oxide loaded with gold nanostars and doxorubicin for combined photothermal and chemotherapy of metastatic breast cancer. Adv Healthc Mater. 2016;5(17):2227-36. https://doi.org/10.1002/adhm.201600283.

Wang C, Zhang Z, Chen B, Gu L, Li Y, Yu S. Design and evaluation of galactosylated chitosan/graphene oxide nanoparticles as a drug delivery system. J Colloid Interface Sci. 2018;516:332-41. https://doi.org/10.1016/j.jcis.2018.01.073.

Wang X, Yu G, Zhang J, Yu M, Ramakrishna S, Long Y. Conductive polymer ultrafine fibers via electrospinning: preparation, physical properties and applications. Prog Mater Sci. 2021;115: 100704. https://doi.org/10.1016/j.pmatsci.2020. 100704.

Wen LY, Bae SM, Do JH, Park KS, Ahn WS. The effects of photodynamic therapy with photodithazine on hpv 16 e6/e7 associated cervical cancer model. J Porphyrins Phthalocyanines. 2011;15(3):174-80. https://doi.org/10.1142/S1088 424611003082.

Wu C, He Q, Zhu A, Li D, Xu M, Yang H, Liu Y. Synergistic anticancer activity of photo- and chemoresponsive nanoformulation based on polylysine-functionalized graphene. ACS Appl Mater Interfaces. 2014;6(23):21615-23. https://doi. org/10.1021/am5066128.

Wu SY, An SS, Hulme J. Current applications of graphene oxide in nanomedicine. Int J Nanomed. 2015;10:9-24. https:// doi.org/10.2147/JN.S88285.

Xu WP, Zhang LC, Li JP, Lu Y, Yu SH. Facile synthesis of silver@graphene oxide nanocomposites and their enhanced antibacterial properties. J Mater Chem. 2011;21(12):4593-7. https://doi.org/10.1039/C0JM03376F.

Xu W, Kattel K, Park JY, Chang Y, Kim TJ, Lee GH. Paramagnetic nanoparticle T1 and T2 MRI contrast agents. Phys Chem Chem Phys. 2012;14(37):12687-700. https://doi.org/10.1039/c2cp41357d.

Xu Z, Wang S, Li Y, Wang M, Shi P, Huang X. Covalent functionalization of graphene oxide with biocompatible poly(ethylene glycol) for delivery of paclitaxel. ACS Appl Mater Interfaces. 2014;6(19):17268-76. https://doi.org/10. 1021/am505308f.

Xu H, Fan M, Elhissi AM, Zhang Z, Wan KW, Ahmed W, Phoenix DA, Sun X. PEGylated graphene oxide for tumor-targeted delivery of paclitaxel. Nanomedicine. 2015;10(8):1247-62. https://doi.org/10.2217/nnm.14.233.

Xu Y, Yu H, Chudal L, Pandey NK, Chen W. Striking luminescence phenomena of carbon dots and their applications as a double ratiometric fluorescence probes for h2s detection. Mater Today Phys. 2020;17: 100328. https://doi.org/10. 1016/j.mtphys.2020.100328.

Yan J, Zhang H, Cheng F, He Y, Su T, Zhang X, Zhang M, Zhu Y, Li C, Cao J, He B. Highly stable RGD/disulfide bridgebearing star-shaped biodegradable nanocarriers for enhancing drug-loading efficiency, rapid cellular uptake, and on-demand cargo release. Int J Nanomed. 2018;13:8247-68. https://doi.org/10.2147/IJN.S179906.

Yan J, Chen J, Zhang N, Yang Y, Zhu W, Li L, He B. Mitochondria-targeted tetrahedral DNA nanostructures for doxorubicin delivery and enhancement of apoptosis. J Mater Chem B. 2020;8(3):492-503. https://doi.org/10.1039/c9tb02266j.

Yan J, Zhang N, Zhang Z, Zhu W, Li B, Li L, Pu Y, He B. Redox-responsive polyethyleneimine/tetrahedron DNA/doxorubicin nanocomplexes for deep cell/tissue penetration to overcome multidrug resistance. J Control Release. 2021;329:36-49. https://doi.org/10.1016/j.jconrel.2020.11.050.

Yang K, Zhang S, Zhang G, Sun X, Lee ST, Liu Z. Graphene in mice: ultrahigh in vivo tumor uptake and efficient photothermal therapy. Nano Lett. 2010;10(9):3318-23. https://doi.org/10.1021/nl100996u.

Yang K, Wan J, Zhang S, Zhang Y, Lee ST, Liu Z. In vivo pharmacokinetics, long-term biodistribution, and toxicology of PEGylated graphene in mice. ACS Nano. 2011;5(1):516-22. https://doi.org/10.1021/nn1024303.

Yang HW, Lu YJ, Lin KJ, Hsu SC, Huang CY, She SH, Liu HL, Lin CW, Xiao MC, Wey SP, Chen PY, Yen TC, Wei KC, Ma CC. EGRF conjugated PEGylated nanographene oxide for targeted chemotherapy and photothermal therapy. Biomaterials. 2013a;34(29):7204-14. https://doi.org/10.1016/j.biomaterials.2013.06.007.

Yang K, Feng L, Shi X, Liu Z. Nano-graphene in biomedicine: theranostic applications. Chem Soc Rev. 2013b;42(2):530-47. https://doi.org/10.1039/c2cs35342c.

Yang L, Tseng YT, Suo G, Chen L, Yu J, Chiu WJ, Huang CC, Lin CH. Photothermal therapeutic response of cancer cells to aptamer-gold nanoparticle-hybridized graphene oxide under NIR illumination. ACS Appl Mater Interfaces. 2015;7(9):5097-106. https://doi.org/10.1021/am508117e.

Yang J, Zhai S, Qin H, Yan H, Xing D, Hu X. NIR-controlled morphology transformation and pulsatile drug delivery based on multifunctional phototheranostic nanoparticles for photoacoustic imaging-guided photothermal-chemotherapy. Biomaterials. 2018;176:1-12. https://doi.org/10.1016/j.biomaterials.2018.05.033.

Yao M, Ma L, Li L, Zhang J, Lim RX, Chen W, Zhang Y. A new modality for cancer treatment-nanoparticle mediated microwave induced photodynamic therapy. J Biomed Nanotechnol. 2016;12(10):1835-51. https://doi.org/10. 1166/jbn.2016.2322. 
Yi L, Zhang Y, Shi X, Du X, Wang X, Yu A, Zhai G. Recent progress of functionalised graphene oxide in cancer therapy. J Drug Target. 2019;27(2):125-44. https://doi.org/10.1080/1061186X.2018.1474359.

Yu X, Gao D, Gao L, Lai J, Zhang C, Zhao Y, Zhong L, Jia B, Wang F, Chen X, Liu Z. Inhibiting metastasis and preventing tumor relapse by triggering host immunity with tumor-targeted photodynamic therapy using photosensitizerloaded functional nanographenes. ACS Nano. 2017;11(10):10147-58. https://doi.org/10.1021/acsnano.7b04736.

Yue H, Wei W, Yue Z, Wang B, Luo N, Gao Y, Ma D, Ma G, Su Z. The role of the lateral dimension of graphene oxide in the regulation of cellular responses. Biomaterials. 2012;33(16):4013-21. https://doi.org/10.1016/j.biomaterials.2012.02. 021.

Zare M, Bastami M, Solali S, Alivand MR. Aberrant miRNA promoter methylation and EMT-involving miRNAs in breast cancer metastasis: diagnosis and therapeutic implications. J Cell Physiol. 2018;233(5):3729-44. https://doi.org/10. 1002/jcp.26116.

Zhang M, Cao Y, Chong Y, Ma Y, Zhang H, Deng Z, Hu C, Zhang Z. Graphene oxide based theranostic platform for T1-weighted magnetic resonance imaging and drug delivery. ACS Appl Mater Interfaces. 2013;5(24):13325-32. https://doi.org/10.1021/am404292e.

Zhang D, Wu M, Zeng Y, Wu L, Wang Q, Han X, Liu X, Liu J. Chlorin e6 conjugated poly(dopamine) nanospheres as PDT/ PTT dual-modal therapeutic agents for enhanced cancer therapy. ACS Appl Mater Interfaces. 2015a;7(15):8176-87. https://doi.org/10.1021/acsami.5b01027.

Zhang H, Wu H, Wang J, Yang Y, Wu D, Zhang Y, Zhang Y, Zhou Z, Yang S. Graphene oxide-BaGdF5 nanocomposites for multi-modal imaging and photothermal therapy. Biomaterials. 2015b;42:66-77. https://doi.org/10.1016/j.bioma terials.2014.11.055.

Zhang Y, Dai T, Wang M, Vecchio D, Chiang LY, Hamblin MR. Potentiation of antimicrobial photodynamic inactivation mediated by a cationic fullerene by added iodide: in vitro and in vivo studies. Nanomedicine. 2015c;10(4):603-14. https://doi.org/10.2217/nnm.14.131.

Zhang Z, Wang M, Gao D, Luo D, Liu Q, Yang J, Li Y. Targeted Raman imaging of cells using graphene oxide-based hybrids. Langmuir ACS J Surf Colloids. 2016;32(40):10253-8. https://doi.org/10.1021/acs.langmuir.6b02248.

Zhang B, Wang Y, Liu J, Zhai G. Recent developments of phototherapy based on graphene family nanomaterials. Curr Med Chem. 2017a;24(3):268-91. https://doi.org/10.2174/0929867323666161019141817.

Zhang DY, Zheng Y, Tan CP, Sun JH, Zhang W, Ji LN, Mao ZW. Graphene oxide decorated with Ru (II)-polyethylene glycol complex for lysosome-targeted imaging and photodynamic/photothermal therapy. ACS Appl Mater Interfaces. 2017b;9(8):6761-71. https://doi.org/10.1021/acsami.6b13808.

Zhang P, Wang Y, Lian J, Shen Q, Wang C, Ma B, Zhang Y, Xu T, Li J, Shao Y, Xu F, Zhu JJ. Engineering the surface of smart nanocarriers using a $\mathrm{pH}$-/thermal-/GSH-responsive polymer zipper for precise tumor targeting therapy in vivo. Adv Mater. 2017c. https://doi.org/10.1002/adma.201702311.

Zhang Q, Wu Z, Li N, Pu Y, Wang B, Zhang T, Tao J. Advanced review of graphene-based nanomaterials in drug delivery systems: synthesis, modification, toxicity and application. Mater Sci Eng C Mater Biol Appl. 2017d;77:1363-75. https://doi.org/10.1016/j.msec.2017.03.196.

Zhang XJ, Cai WB, Hao LY, Hu XH, Wei XJ, Wang XY. Preparation of thermo/ph-sensitive reduced graphene oxide interpenetrating hydrogel nanocomposites for co-delivery of paclitaxel and epirubicin. Mater Technol. 2017e. https://doi. org/10.1080/10667857.2017.1410987.

Zhang C, Liu Z, Zheng Y, Geng Y, Han C, Shi Y, Sun H, Zhang C, Chen Y, Zhang L, Guo Q, Yang L, Zhou X, Kong L. Glycyrrhetinic acid functionalized graphene oxide for mitochondria targeting and cancer treatment in vivo. Small. 2018. https://doi.org/10.1002/smll.201703306.

Zhang Y, Chen S, An J, Fu H, Wu X, Pang C, Gao H. Construction of an antibacterial membrane based on dopamine and polyethylenimine cross-linked graphene oxide. ACS Biomater Sci Eng. 2019;5(6):2732-9. https://doi.org/10.1021/ acsbiomaterials.9b00061.

Zhang X, Liang T, Ma Q. Layer-by-layer assembled nano-drug delivery systems for cancer treatment. Drug Deliv. 2021;28(1):655-69. https://doi.org/10.1080/10717544.2021.1905748.

Zhao L. A novel graphene oxide polymer gel platform for cardiac tissue engineering application. 3 Biotech. 2019;9(11):401. https://doi.org/10.1007/s13205-019-1912-4.

Zhao X, Wei Z, Zhao Z, Miao Y, Qiu Y, Yang W, Jia X, Liu Z, Hou H. Design and development of graphene oxide nanoparticle/chitosan hybrids showing $\mathrm{pH}$-sensitive surface charge-reversible ability for efficient intracellular doxorubicin delivery. ACS Appl Mater Interfaces. 2018;10(7):6608-17. https://doi.org/10.1021/acsami.7b16910.

Zhen Z, Tang W, Chuang YJ, Todd T, Zhang W, Lin X, Niu G, Liu G, Wang L, Pan Z, Chen X, Xie J. Tumor vasculature targeted photodynamic therapy for enhanced delivery of nanoparticles. ACS Nano. 2014;8(6):6004-13. https://doi.org/10. 1021/nn501134q.

Zhi X, Fang H, Bao C, Shen G, Zhang J, Wang K, Guo S, Wan T, Cui D. The immunotoxicity of graphene oxides and the effect of PVP-coating. Biomaterials. 2013;34(21):5254-61. https://doi.org/10.1016/j.biomaterials.2013.03.024.

Zhou T, Zhou X, Xing D. Controlled release of doxorubicin from graphene oxide based charge-reversal nanocarrier. Biomaterials. 2014;35(13):4185-94. https://doi.org/10.1016/j.biomaterials.2014.01.044.

Zhu S, Meng Q, Wang L, Zhang J, Song Y, Jin H, Zhang K, Sun H, Wang H, Yang B. Highly photoluminescent carbon dots for multicolor patterning, sensors, and bioimaging. Angew Chem. 2013;52(14):3953-7. https://doi.org/10.1002/ anie.201300519 (International ed. in English).

Zou X, Yao M, Ma L, Hossu M, Han X, Juzenas P, Chen W. X-ray-induced nanoparticle-based photodynamic therapy of cancer. Nanomedicine. 2014;9(15):2339-51. https://doi.org/10.2217/nnm.13.198.

Zou X, Zhang L, Wang Z, Luo Y. Mechanisms of the antimicrobial activities of graphene materials. J Am Chem Soc. 2016;138(7):2064-77. https://doi.org/10.1021/jacs.5b11411.

\section{Publisher's Note}

Springer Nature remains neutral with regard to jurisdictional claims in published maps and institutional affiliations. 